\title{
POÉTICA Y RETÓRICA DIALÓGICA DEL ESPACIO EN LA CIUDAD DE MÉXICO
}

\author{
Jacob Bañuelos Capistrán \\ Cátedra de Semiótica \\ Departamento de Comunicación y Periodismo \\ Tecnológico de Monterrey- Campus Ciudad de México \\ jcapis@itesm.mx
}

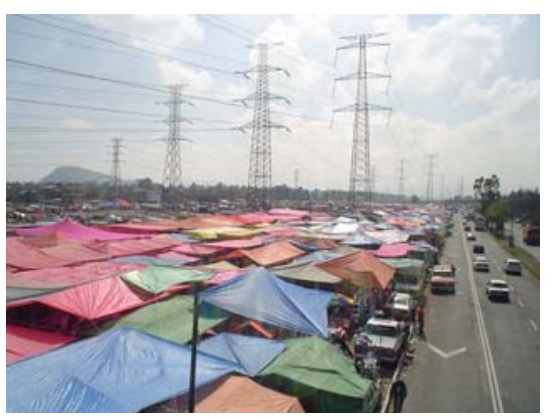

\section{Resumen}

El presente estudio analiza la complejidad del espacio en la Ciudad de México, Distrito Federal (D.F.), ciudad con más de 20 millones de habitantes, en donde la aglomeración espacial es el factor definitorio. Se propone identificar visualmente las cualidades de la poética del espacio y sus relaciones con base en:

1. Matrices espacio-temporales: premodernos, modernos y posmodernos; identificación de por lo menos un elemento arquitectónico de cada matriz. 
2. Poética dialógica del espacio, análisis de la construcción poética del espacio en la ciudad de México: identificación de las relaciones poéticas relevantes y las constantes de aglomeración en el espacio de la ciudad desde una perspectiva histórica y sociocultural.

Se propone así, identificar visualmente los elementos (signos=objetos) urbanos constantes de la aglomeración, así como sus constantes espacio-temporales, es decir, identificar qué signos definen las relaciones poéticas y la aglomeración en la ciudad de México en términos espaciales.

\section{Palabras clave}

Póetica del espacio - Matrices espacio-temporales - Signos arquitectónicos -Cronotopos - Ciudad de México.

\section{Abstract}

The study analizes the complexity of the space in Mexico City, Distrito Federal (D.F.).

D.F. is a city with more than 20 million inhabitants where the spacial agglomeration is the definible factor. The purpose is to visually identify qualities of the the poetics of space and its relation based in:

1.-Space-temporal matrixes: pre-moderns, moderns and post-moderns. To identify at least one architectonic element of each matrix

2.- Dialogic poetics of the space, analysis of the poetics of the space construction of Mexico City: Identification of the relevant poetic relations and the agglomeration constants in the space of the city from a historic and socio-cultural perspective.

Therefore, it is proposed to visually identify the constant urban elements (signs=objects) of the agglomeration, as well as its space-temporal constants. This means, to identify which signs define the poetic relationships and the Mexico City agglomeration in spacial terms.

\section{Key words}

Poetics of the space- Space-temporal matrixes- Architectonic signs- Cronotopos - México City. 


\title{
1. Poética dialógica del espacio aglomerado: Ciudad de México
}

\author{
"El significado del espacio es \\ un terreno singularmente neutral para la interpretación”.
} Steve Yates (1).

La imagen poética es la otredad o alteridad. El fenómeno moderno de la incomunicación no depende tanto de la pluralidad de sujetos cuanto de la desaparición del tú como elemento constitutivo de cada conciencia. No hablamos con los otros porque no podemos hablar con nosotros mismos. Pero la multiplicación cancerosa del yo no es el origen, sino el resultado de la pérdida de la imagen del

mundo.

Octavio Paz (2)

En el presente estudio, entendemos la arquitectura como signos-objetos, autorreferenciales, cuyo origen formal, estilístico, funcional, cultural e interpretativo corresponde a diversas concepciones del tiempo y el espacio, y que adquieren diversos sentidos semánticos según el usuario y la perspectiva desde la cual se analicen. Nos interesa plasmar un análisis desde una perspectiva histórica de dichos signos, y armar un modelo sintagmático para describir sus relaciones. Es preciso subrayar e insistir que los objetos arquitectónicos aquí analizados son considerados los signos textualizados que dan orden y desorden al espacio en el contexto de la Ciudad de México, mayojunio de 2004, y que se analizan desde una perspectiva histórica.

Dicho modelo sintagmático propuesto, es igualmente un intento por representar la poética arquitectónica del espacio en la Ciudad de México. Nuestra hipótesis es que dicho espacio arquitectónico plantea relaciones poéticas de tipo dialógico, intersectadas por constantes de aglomeración urbana que dan un modelo semiótico de la Ciudad de México.

Advertencia: el presente estudio es una aproximación inicial al estudio de la poética del espacio arquitectónico en la Ciudad de México, y el modelo semiótico descriptivo que se ha elaborado, es un modelo experimental que se encuentra en etapa de construcción e investigación, de ninguna forma se 
platea como definitivo en cuanto a sus resultados, ni en cuanto al modelo teórico que exige mayor elaboración, por lo que igualmente el texto presente se considera un apunte inicial para futuras y próximas investigaciones sobre el tema.

\subsection{Delimitación conceptual}

Entendemos por poética dialógica del espacio aglomerado en la Ciudad de México, aquellas relaciones semióticas entre los signos arquitectónicos como orden del espacio, que generan desvíos de ese orden histórico del espacio. Dichos desvíos poéticos, se realizan en las intersecciones históricas que dichos signos/objetos arquitectónicos generan entre sí, dentro del gran conjunto arquitectónico del espacio en la Ciudad de México, y en medio de las prácticas y usos tradicionales y contemporáneos de dicho espacio.

Concebimos una poética del espacio, como bien apunta Yates, como una estructura abarcadora, virtual, dentro de la cual diversos puntos de vista contribuyen a darle forma. Del mismo modo, como apunta Rudolf Arnheim, en el siglo XX el espacio dejó de estar vacío para convertirse en un territorio de fuerzas donde las cosas interactúan, para llenarse de sucesos dramáticos, sucesos que cuando se les da una forma artística, se convierten en imágenes poéticas. (Yates, 2002, p. 26)

Traduciremos a imágenes de la ciudad, estas relaciones poéticas en el espacio de la Ciudad de México, que ocurren en el conjunto de las relaciones sígnicas que la arquitectura del espacio establece en la ciudad de México.

Como sabemos, función poética, siguiendo a Jakobson, consiste en transgredir de manera intencional o no intencional, una norma estándar, un código de representación visual, estética, lógica, semántica o ideológica. Las relaciones entre los elementos componentes de la arquitectura urbana y las figuras creadas permiten interacciones semánticas, culturales y estéticas, revelando sus correspondencias (por identidad, similitud, diferencia u oposición), que se suman a la significación de la arquitectura como signo específico, como objeto significante, y revelan en su interior una acumulación de elementos estructurales, una construcción compleja, un discurso sobreelaborado.

Poética dialógica, es un concepto de interrelaciones dinámicas, un “diálogo” de desvíos poéticos arquitectónicos, organizados sintagmáticamente desde intersecciones históricas arquitecturales. Relaciones dialógicas dinámicas, de tipo sintáctico, semántico y pragmático; de tipo histórico, estilístico, cultural y estético. El discurso poético dialógico se caracteriza porque expresa algo que 
está más allá de lo físicamente representado, caracterizado por la suma de las interrelaciones semánticas dadas.

Por espacio coincidimos con Rudolf Carnap, dados sus conceptos objetivos, subjetivos y materiales, como categorías de “espacio formal”, “espacio percibido” y “espacio físico”. Siguiendo a Carnap, el espacio formal, puede definirse como una formación única de relaciones entre partes indeterminadas de una forma en la que una asociación sigue a otra en un mismo terreno. El espacio formal incluye objetos relacionados de manera significante cuyas relaciones están sometidas a condiciones formales, representadas por diversas entidades como números, colores, o interpretaciones, es decir, signos organizados de diversa manera en órdenes sintácticos, semánticos y pragmáticos. (Yates, 2002, p.119-128)

El espacio aglomerado es una realidad en la Ciudad de México, dada en la experiencia sensorial, formal, perceptual y física. Siguiendo a Moholy-Nagy, el espacio aglomerado se percibe mediante signos visuales formales como: perspectivas, superficies que se encuentran y se cortan mutuamente, esquinas, objetos en movimiento con intervalos entre ellos, objetos que se penetran mutuamente, relaciones de masa, luz, color, textura, tensión; mediante signos sonoros: según fenómenos acústicos; mediante la observación del movimiento: en distintas direcciones en el espacio; mediante medios de locomoción; horizontal, vertical, diagonal, intersecciones, saltos; mediante el sentido del equilibrio: círculos, triángulos, cuadrados, curvas, espirales, planos. (citado por, Yates, 2002, p. 208-209)

El espacio contemporáneo se caracteriza por su eclecticismo, en donde los límites se hacen “fluidos” dado que el espacio se concibe como algo que fluye, como una interminable sucesión de relaciones poéticas y retóricas.

Finalmente, el concepto de aglomeración está entendido aquí como una constante en el espacio arquitectónico urbano. La aglomeración como producto de la saturación arquitectónica del orden del espacio. Aglomeración es igual a saturación de signos/objetos en el orden/desorden del espacio urbano. Las constantes de aglomeración en la Ciudad de México sirven igualmente como puntos de intersección en las relaciones espacio-temporales de la propia ciudad, y las identificamos más adelante. 


\subsection{Función poética y estética en la arquitectura del espacio de la Ciudad de México}

Para Roman Jakobson la función poética es “la tendencia hacia el mensaje como tal”, pues en ella el signo/objeto arquitectónico se refiere a sí mismo. Jakobson se refiere al arte verbal y literario, aunque reconoce los fenómenos poéticos en todo tipo de expresión artística y humana. Sus deducciones son aplicables al objeto arquitectónico. Jakobson afirma que para conocer los rasgos inherentes a la poesía, es necesario recurrir a los modelos básicos que se utilizan en una conducta verbal. Tales modelos básicos son aplicables a la conducta de articular el espacio mediante la arquitectura: la selección y la combinación.

Equivalente al concepto de “función poética” de Jakobson, encontramos el de "función estética” de Jan Mukarovsky, que también nos ayuda a situar el carácter poético de la arquitectura y poética del espacio aglomerado en la cudad.

Para Mukarovsky la función estética puede ser observada dentro y fuera del arte. Desde dos perspectivas, desde el punto de vista del sujeto y desde el punto de vista del objeto.

Desde el punto de vista del signo-objeto arquitectónico, la función estética es el papel que cumple la arquitectura del espacio entre los individuos, en la sociedad; función que abarca otros objetos y acciones que también cumplen una función estética fuera del arte, como la mayor parte de las producciones publicitarias; mientras los objetos y acciones de carácter estrictamente artístico pueden llegar a perder su función. Los límites de la función estética no sólo están determinados por las acciones y los objetos, sino principalmente por los receptores que los interpretan.

La afirmación que nos parece más interesante en Mukarovsky, es que la estabilización de la función estética es asunto de la colectividad.

Para Umberto Eco, la función estética se da cuando el signo arquitectónico se estructura de manera ambigua y se presenta como autorreflexivo al atraer la atención del destinatario antes que nada hacia su propia forma. La describe en los mismos términos en que Jakobson lo hace respecto a la función poética. (3)

Como obra visual inmersa en una colectividad histórica-cultural dada, la arquitectura como signo/onbjeto en la Ciudad de México asume una función poética y una función estética, determinadas por los individuos que la perciben e interpretan, por el contexto (tiempo y espacio históricos), por la “dominante” (si la hay) de la expresión estética, por el campo semántico donde se 
presenta la obra y por las características propias de la poética del arquitecto o de la intención arquitectónica.

La figura retórica arquitectónica por sí sola no es suficiente para producir el efecto de sentido que el espectador encuentra en la arquitectura del espacio aglomerado. El efecto poético se construye en el espectador, en el ethos/efecto producido en la relación de la obra y el espectador. La retórica es un medio de la poética y está en las intenciones del autor, pero fundamentalmente está o no, en el receptor de la obra.

En la arquitectura del espacio, nuestra vinculación con el mundo quizás esté presente, quizás se encuentre establecida, pero no probada científicamente. La información plasmada es poética, científica, estética, mítica, fantástica, simbólica, ideológica, individual y social. Su potencia y debilidad radican en la con-fusión voluntaria entre la intersección de sujetos, elementos expresivos, signos, materiales y su reunión.

\section{Ciudad de México, Distrito Federal}

Ciudad de México, Distrito Federal es capital de los Estados Unidos Mexicanos, República Mexicana, fundada en 1325 por los mexicas. Es hasta el siglo XIII cuando llega a la zona, proveniente de Aztlán (sitio tal vez mítico) el grupo mexica cuyo dios tutelar Huizilopochtli (Zurdo Colibrí) representa un carácter austero y guerrero. Conducidos por el sacerdote Tenoch, luchan contra los pueblos establecidos para conseguir un sitio en las riveras de los lagos. Hacia 1299 se establecen en Chapultepec, lugar privilegiado por su posición estratégica y recursos naturales, pero son expulsados por los Acohuas hacia un islote en el lago.

(http://www.mexicocity.com.mx/historia1.html\#Fundaci-n)

Es allí donde concluye la peregrinación secular de los mexicas; la señal para ello fue la visión de un águila devorando una serpiente sobre una planta de nopal que crecía sobre un islote. Fue así como se funda la ciudad de México-Tenochtitlan el 8 de junio de 1325.

(http://www.mexicocity.com.mx/historia1.html\#Fundaci-n)

La ciudad se construyó sobre un desecado conjunto de lagos donde hoy viven cerca de 20 millones de habitantes a un ritmo acelerado y contrastante que se nota en la diversidad de actividades que transcurren en sus calles: automóviles en nervioso trayecto, innumerables peatones, comedores en las esquinas y vendedores de todo tipo. En este escenario tiene cabida la pobreza de muchos de 
sus habitantes, pero también el refinamiento y el lujo.

(http://www.mexicocity.com.mx/historia1.html\#Fundaci-n)

En 1824 se restableció la República y el congreso decretó que la Ciudad de México se separara administrativamente del estado del mismo nombre con un territorio dividido en cuarteles y con el nombre de Distrito Federal. (http://www.mexicocity.com.mx/historia1.html\#Fundaci—n)

El Distrito Federal cuenta con una población de 8 millones 605 mil 239 habitantes, de los cuales 4 millones 110 mil 485 son hombres y 4 millones 494 mil 754 son mujeres. El Distrito Federal representa el $0.1 \%$ de la superficie del país.

\subsection{Zona Metropolitana y ritmo de crecimiento poblacional}

Actualmente, según el más reciente censo (año 2000) del Insituto Nacional de Estadística Geografía e Informática (INEGI), la zona metropolitana que comprende la Ciudad de México, reporta una población de 16, 6 millones de habitantes. Está considerada la segunda ciudad más grande del mundo, después del corredor Tokio-Yokohama, en Japón. Con una superficie total de 149, 525 ha, de las cuales 61, 081 ha son de suelo urbano y 88, 442 ha son suelo de conservación, situado en el eje neovolcánico transversal, una de las zonas del país con mayor concentración de especies endémicas. (fuente: Secretaría del Medio Ambiente, Comisión de Recursos Naturales y Desarrollo Rural, Dirección Ejecutiva de Ordenamiento Ecológico).

La zona metropolitana de la Ciudad de México, comprende el Distrito Federal y 27 municipios del Estado de México, y hacia 1990 tenía 15 millones de habitantes, es decir, 18.4\% de la población del país. (todos los datos de esta sección ha sido tomados de:

http://www.mexicocity.com.mx/crecer.html. Ver también: Guillermo Olivera en http://www.bancomext.gob.mx/esp/olivera.html)

“En 1970 tenía 9 millones de habitantes y en 1980, 14 millones. En el decenio de los años setenta creció $4.5 \%$ al año y en el de los ochenta sólo $0.7 \%$.

Este crecimiento obedeció a la dinámica social y económica imperante en la posguerra. El relativo aislamiento del país en materia de transacciones comerciales obligó a las empresas a concentrarse en el mercado interno y, en particular, en el mayor mercado del país: la Ciudad de México. Esto propició la creación de una 
importante infraestructura y que todas las vías de comunicacion confluyeran en ella. También el centralismo del gobierno federal influyó en esta tendencia. El crecimiento demográfico de la Ciudad se aceleró, junto con el de la industria manufacturera y los servicios, como fuentes de empleo.

Se calcula que en 1995 la población de la Ciudad era de 15.5 millones de habitantes.

Como se aprecia, la Ciudad ha reducido su ritmo anual de crecimiento a una tasa menor que la de la población nacional (2\%) y que la de la urbana (3.7\%). Es, asimismo, la metrópoli con menor crecimiento del país.

Ello obedece, en lo fundamental, a un cambio en la distribución de la vida económica del país, la cual se ha desconcentrado de manera importante. En tal fenómeno ha sido fundamental la apertura de la economía a las transacciones con el exterior. En particular, la necesidad de exportar y la inversión extranjera en el país han determinado la nueva localización de plantas productivas y de las empresas en general. Esto se traducirá eventualmente en una redistribución de la población en busca de empleos y mejores ingresos.

Debido a los costos que implica para las empresas asentarse en esta urbe y a la infraestructura con que cuenta, tanto humana como material, la Ciudad se ha convertido en sede, sobre todo, de oficinas corporativas de grandes empresas y de compañías innovadoras y de alta tecnología, así como centro financiero del país.

Así, es claro que el crecimiento de la Ciudad de México será cada vez menor $y$, de continuar las tendencias descritas, es muy improbable que se acerque en el mediano plazo a los 20 millones de habitantes, como alguna vez se pensó, por lo menos en la zona que comprenden el Distrito Federal y los municipios conurbados”. (sic. http://www.mexicocity.com.mx/crecer.html) 


\begin{tabular}{|c|c|}
\hline ASPECTO & CIFRAS \\
\hline Superficie total del Distrito & 149,524 \\
\hline Federal & ha \\
\hline Suelo urbano & 61,082 \\
\hline & ha \\
\hline Suelo de conservación* & 88,442 \\
\hline & ha \\
\hline Zona de recarga natural de los & $59.1 \%$ \\
\hline mantos acuíferos o suelo de & del \\
\hline conservación & territorio \\
\hline & del \\
\hline & Distrito \\
\hline & Federal $^{a}$ \\
\hline Área de recarga del Ajusco, de la & 1825 \\
\hline Sierra de Guadalupe y de la Sierra & $\mathrm{km}^{2 a}$ \\
\hline de Chichinautzin & \\
\hline \multicolumn{2}{|c|}{$\begin{array}{l}\text { *Se sitúa en el eje neovolcánico transversal, una de } \\
\text { las zonas del país con mayor concentración de } \\
\text { especies endémicas }\end{array}$} \\
\hline Extracción de agua en esta área & 923 \\
\hline de recarga & millones \\
\hline & de $m^{3}{ }^{a}$ \\
\hline $\begin{array}{l}\text { Agua que provee para el consumo } \\
\text { de la ciudad }\end{array}$ & $57 \%^{a}$ \\
\hline Capacidad de captura de carbono & $\begin{array}{l}90 \\
\text { ton/ha }\end{array}$ \\
\hline $\begin{array}{l}\text { Riqueza biológica mundial que } \\
\text { alberga }\end{array}$ & $2 \%$ \\
\hline $\begin{array}{l}\text { Riqueza biológica nacional que } \\
\text { alberga }\end{array}$ & $11 \%$ \\
\hline
\end{tabular}




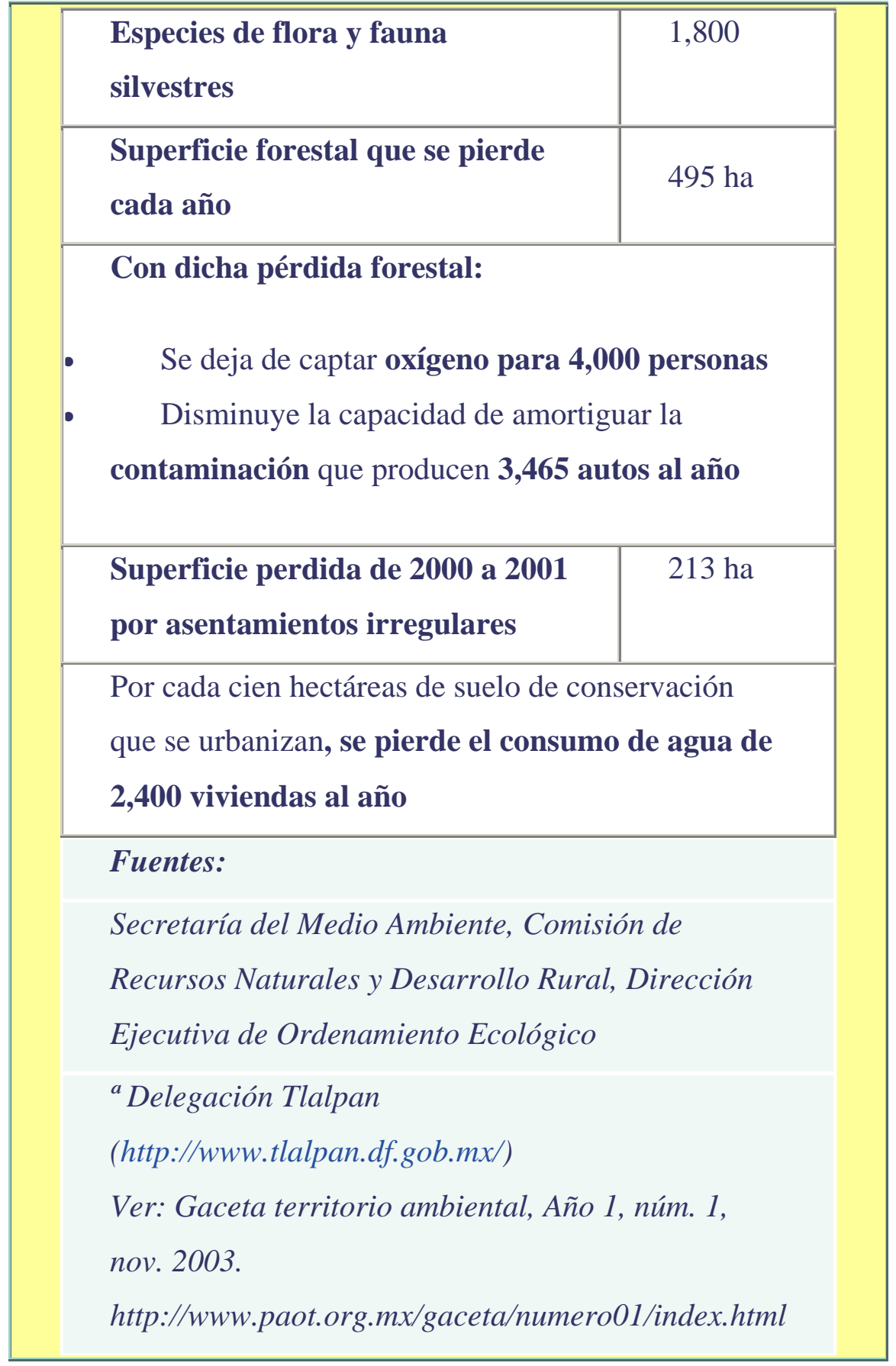


4. Gustavo A. Madero

5. Iztacalco

6. Iztapalapa

7. Magdalena Contreras, La

8. Milpa Alta

9. Alvaro Obregón

10. Tláhuac

11. Tlalpan

12. Xochimilco

13. Benito Juárez

14. Cuauhtémoc

15. Miguel Hidalgo

16. Venustiano Carranza

\section{Signos arquitectónicos premodernos, modernos, posmodernos y emergentes}

En el Distrito Federal encontramos cuatro tipos de signos arquitectónicas que ordenamos aquí históricamente, de acuerdo a cuatro matrices espacio-temporales, a las que corresponde cada uno de los cuatro tipos de signos y que se integran en un paisaje ecléctico contemporáneo.

Más adelante describimos brevemente las cualidades de cada una de estas matrices espaciotemporales en un modelo semiótico de tipo sintáctico y descriptivo, en las que se inscriben dichos signos arquitectónicos.

\subsection{Signos arquitectónicos premodernos}

En la Ciudad de México encontramos signos arquitectónicos premodernos que corresponden a la época mexica (o azteca), y que fueron construidas entre el año 800 y 300 a.C., período denominado 
Preclásico, y el período que va de 900 a 1521 denominado Postclásico, que aquí enmarcamos en lo “premoderno”. De acuerdo con Pazos, hay divergencias entre los historiadores en cuanto a las fechas y divisiones, “algunos agregan un período prehistórico antes del preclásico, otros hablan del clásico tardío dentro del clásico y algunos añaden el horizonte histórico después del preclásico”. (Pazos, Luis, 1993, p.19)

Cronotopo 1. Territorio/cíclo: Los signos arquitectónicos premodernos, se inscriben como acontecimientos en una matriz espacio-temporal de “necesidad” territorial y cíclica. Delimitamos las más relevantes en la ciudad, que además simbolizan claramente la arquitectura histórica fundacional y las relaciones poéticas de los signos arquitectónicos en la ciudad, son:

a. Cuicuilco (800 a.C.-300 a.C. / Preclásico)

b. Templo Mayor (1300-1521 d.C./ Postclásico)

c. Tlatelolco (1338 d.C/ Postclásico)

\subsection{Signos arquitectónicos modernos}

Entendemos por modernos, los signos arquitectónicos herederos del Renacimiento y que llegan a la Ciudad de México después de 1500, instaurando estilísticas y concepciones espaciales que corresponden a todo un movimiento de pensamiento denominado moderno.

Cronotopo 2. Espacio abstracto/tiempo lineal: Los signos arquitectónicos modernos, se inscriben en una matriz espacio-temporal de “posibilidad” en donde la concepción espacial es abstracta y el temporalidad es conceptualmente lineal.

d. Catedral de México. Arq. Claudio de Arciniega (1573)

e. Iglesia de Santiago Tlatelolco (1609)

f. Palacio de Bellas Artes (1904-1934) 


\subsection{Signos arquitectónicos posmodernos}

Los signos arquitectónicos posmodernos, son concebidos aquí como aquellos construidos durante la segunda mitad del siglo XX, y cuya característica principal es su eclecticismo formal, con un alto índice de funcionalidad en su propósito, realizando fuertes antagonismos y fusiones arquitectónicas en relación a su entorno.

Cronotopo 3. Espacio utópico/tiempo ucrónico: Los signos arquitectónicos posmodernos se inscriben en una conceptualización que los origina, específica, y el marco de una matriz espaciotemporal de “imposibilidad” ucrónica y utópica.

g. Conjunto Habitacional Nonoalco - Tlatelolco. Plaza De las Tres Culturas. Arq. Mario Pani (1962-1964)

h. Complejo Santa Fe (1990-2004):

1. Corporativo Arcos Bosques, Santa Fe, Ciudad de México.

Arq. Teodoro González de León (1990-1996)

2. Corporativo Calakmul, Santa Fe, Ciudad de México.Arq. Agustín

Hernández. Edificio Inteligente. Alta Tecnología arquitectónica. (19941997).

i. Centros Comerciales:

-Centro comercial Perisur. Arq. Sordo Madaleno (1982)

- Centro Comercial Santa Fe (1993),

j. Viviendas hiper-aglomeradas Cujimalpa (1970-2000)

\subsection{Signos arquitectónicos emergentes}

Entendemos por signos arquitectónicos emergentes, aquellos que surgen de evolución contemporánea de la Ciudad de México y que la caracterizan actualmente.

Cronotopo 4. espacio sitio/tiempo momento: Los signos de este orden emergente del espacio urbano, se insertan en una matriz espacio-temporal de "contingencia” en donde el lugar es el "sitio" y el tiempo es el "momento".

k. Segundos pisos del Periférico y Viaducto (2003)

1. Distribuidor Vial San Antonio (2002). 


\subsection{Signos urbanos como constantes de aglomeración en la Ciudad de México}

Identificamos dos constantes de aglomeración dominantes contemporáneas (año 2004) en la Ciudad de México. Son signos arquitectónicos que propician la transitoriedad espacio-temporal, y aparecen igualmente como signos de intersección y vinculación del uso del espacio urbano en la Ciudad de México. Igualmente son los signos que revelan el hacinamiento, la sobrepoblación urbana, la saturación de signos/objetos en el espacio de la Ciudad y la falta de planeación urbanística de la cual son origen. Igualmente, estos signos constantes de aglomeración, construyen una poética entendida como el desvío del orden urbano que propiciado entre los diferentes tipos de signos.

Cronotopo 4. Espacio sitio/tiempo momento: También observamos que los signos de aglomeración constante corresponden a una matriz espacio-temporal de “contingencia” en donde el lugar es el “sitio” y el tiempo es el “momento”. Tales signos son:

m. Tránsito vehicular. Circulan más de 3 millones de automóviles circulan diaramente (2004)

n. Mercados ambulantes. 50 mercados “tianguis" diarios. Y 5,000 vendedores ambulantes en el la Zona Metropolitana de la Ciudad de México (2004)

\section{Cronotopos o matrices espacio-temporales de los signos arquitectónicos: Ciudad de México}

Cuando hablamos de matrices espacio-temporales de los signos arquitectónicos, nos referimos a los cronotopos en los que se inscriben dichos signos/objetos como forma de representación, como acontecimiento y como construcción espacial urbana. Dichas matrices condicionan al sujeto a relacionarse con el espacio de una o de otra forma.

Para el presente análisis hemos retomado las modalidades aléticas propuestas en el cuadro semiótico dado por Greimas y Courtés, y trabajado posteriormente por Gonzalo Abril para describirlo en términos de categorías espacio-temporales o cronotopos. Lo que hacemos aquí es una aplicación específica del cuadro al análisis histórico de los signos arquitectónicos como orden del espacio en la Ciudad de México, para establecer sus relaciones dialógicas y poéticas. En el presente 
apartado seguiremos el análisis puntual de Abril, que elabora para describir los fenómenos de información, representación y discurso contemporáneos. (Abril, 1997, p. 177-185) (4) (5)

Lo primero será describir el cuadro de relaciones espacio-temporales o cronotopos, en el marco de las modalidades aléticas o categorías modales aléticas (semióticas), y más adelante el avance analítico que le hemos dado:

El cuadro semiótico de Greimas y Courtés que utilizamos, parte de la estructura modal del deber-ser (ser/estar), de lo que se infieren las categorías (lógicas) modales siguientes:

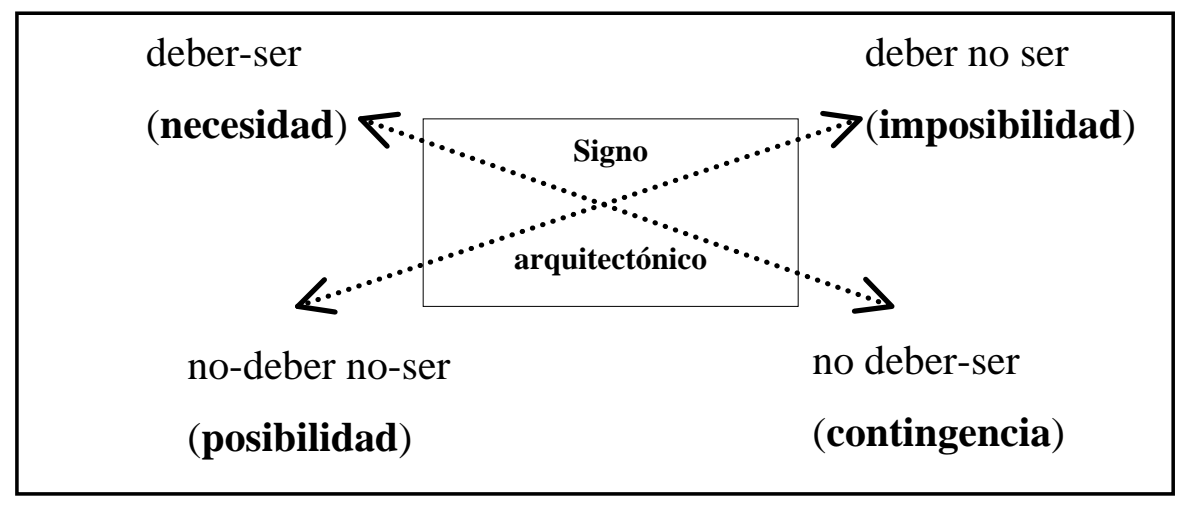

1. Cuadro semiótico de modalidades aléticas, (Greimas y Courtés,

1982: 31).

Las modalidades aléticas son modalidades lógicas, que relativizan el concepto de verdad, es decir, plantean la verdad como una modalidad lógica, no absoluta Con este cuadro semiótico inicial tenemos ya la base teórica a partir de la cual podemos insertar cronotopos, así como matrices espacio-temporales (históricas) para describir el comportamiento y características propias del signo arquitectónico.

Los signos arquitectónicos, se construyen en matrices espacio-temporales como representaciones (o acontecimientos) incorporados a escenarios espaciales y a contextos temporales en virtud de los cuales, como apunta Abril, adquieren sentidos particulares. Esos escenarios espacio-temporales o cronotopos, expresión utilizada por M. Bajtin, expresan además, la existencia de matrices culturales heterogéneas y complementarias (premodernidad, modernidad, posmodernidad) en el decurso de los signos arquitectónicos y en sus relaciones. El presente análisis trata al signo arquitectónico, como signo objeto y como representaciones histórico-culturales del espacio-tiempo. (Abril, 1997, p. 181). 
Los cronotopos surgen del cuadro semiótico de Greimas y Courtés, y son inferidos por analogía del cuadro de modalidades aléticas arriba expuesto, en el que se articulan (1) necesidad, cronotopo 1; (2) la posibilidad, cronotopo 2; (3) la imposibilidad, cronotopo 3; y (4) la contingencia, cronotopo 4.

Así, cada uno de ellos deriva de proyectar sobre el signo espacio-temporal, la categoría alética correspondiente. De tal modo la noción de momento/ sitio (4) es análoga a la de un tiempo/espacio “contingente”, la de tiempo cíclico/territorio (1) a la de un tiempo/espacio "necesario", la de un tiempo lineal/abstracto (2) a la de un tiempo/espacio de "posibilidad”, y finalemente la noción tiempo ucrónico/espacio utópico (3) a la de un tiempo/espacio de “imposibilidad”.

Además dichos cronotopos derivan en las matrices espacio-temporales que se describen como premodernas, modernas, posmodernas y emergentes, que responden a nociones de tipo cultural e histórica.

a) Cronotopo 1. Territorio/cíclo: Corresponde a una matriz espacio-temporal de "necesidad" premoderna. Los signos arquitectónicos responden en la concepción de un tiempo ritual, festivo, mitológico, cíclico. Y el espacio responde a la noción de territorio, el espacio cualitativo de la comunidad premoderna, al espacio experiencial de la vida cotidiana. Como apunta Abril, el territorio se construye en contextos prácticos, experienciales y de interpersonal. Este tipo de espacio es irreductible a descripciones abstractas o descontextualizadas, así como difícil de incorporar modificaciones históricas del espacio, las tradiciones locales pueden conservar la memoria histórica de las referencias espaciales de dichos signos arquitectónicos. Esta noción de territorio, hace referencia a signos/objetos como representaciones de territorios ecológicos, geográfico-productivos, simbólicos, rituales y míticos. El territorio tradicional se define por marcas simbólico-rituales y por narraciones en las que se ha depositado una memoria colectiva. La relación de los sujetos con el espacio se caracteriza por experiencias directas y por vinculaciones afectivas. Los signos arquitectónicos premodernos de la Ciudad de México, corresponden a los templos religiosos y ciudades mexicas o aztecas, y se describen de manera simbólica y ritual. (Abril, 1997, p. 177)

a) Cronotopo 2. Espacio abstracto/tiempo lineal: Corresponde a una matriz moderno ilustrada o histórico formal. Tiempo histórico que organiza los acontecimientos cronológicamente. El 
espacio moderno es un espacio abstracto y formal, de posible representación en mapa o croquis. Los espacios político-administrativos como municipios, departamentos o delegaciones en el caso de la Ciudad de México, son marcos de definición en el espacio moderno. La matriz moderno ilustrada, dejó su huella histórica en toda la arquitectura llamada “colonial” que en la Ciudad de México inicia después de la Conquista de México, hacia 1500 d.C.

b) Cronotopo 3. Espacio utópico/tiempo ucrónico: Corresponde a una matriz espacio/temporal posmoderna, caracterizada por el eclecticismo y la heterogeneidad de signos/objetos arquitectónicos en un mismo espacio urbano. La ucronía produce un efecto de diacronismo e hipercronismo, que no corresponden a una representación única u homogénea. Dicha matriz espacio-temporal, en la que se construyen los signos arquitectónicos posmodernos supone una fractura, superposición, simultaneidades anacrónicas, mezcla e inversión espacio-temporal histórica. Así encontramos edificios funcionalistas herederos de la arquitectura Bauhaus construidos junto a un templo de concepción moderno-ilustrada (La Iglesia de Santiago Tlatelolco (1609), al lado de un templo mexica (Tlatelolco 1338 d.C.) de matriz premoderna, todo unido en el Conjunto Habitacional Tlatelolco o Plaza de las Tres Culturas (1962-1964), próxima al centro de la Ciudad de México.

Igualmente encontramos los desarrollos urbanísticos como Santa Fe o también llamado Lomas de Vista Hermosa, en el que se construyen edificios “inteligentes”, para grandes corporativos empresariales y financieros, de fachada reflectante que producen un efecto de “invisiblidad”. También inscibimos en esta matriz posmoderna a los Centros Comerciales o Mall’s, como Centro Comercial Santa Fe en la misma zona, y Perisur al sur de la Ciudad de México, lugares autorreferenciales, descontextualizados, que incluso puede proponer ficciones transtemporales, y propuestas espaciales cerradas que no remiten a un mundo externo, en un entorno espacial autocontenido, desgajado del exterior, también llamado "hiperespacio” por F. Jameson. (Murdock, 1993:331 citado en Abril, 1997, p. 179).

d) Cronotopo 4. espacio sitio/tiempo momento: Corresponde a una matriz espacio-temporal emergente, de prácticas culturales mediáticas, así como los llamados espacios "efímeros”. Inscribimos en esta matriz la polémica denominación de Marc Auge de los “no lugares”, es decir, lugares de tránsito experiencialmente ubicuos: "La ubicación en un no-lugar es como "la presencia de la ausencia” en el viaje cognitivo dialógico o perceptible. 
Por "momento" se entiende la instantaneidad, el "tiempo real”, el "instante continuo". Por "sitio" se entiende al "lugar móvil” y no anclado territorialmente. Alude igualmente al carácter posicional de la ubicación del sujeto en el espacio. Aquellos signos arquitectónicos creados para el acontecer de estos actos de contingencia, como los grandes puentes elevados que literalmente “emergen” en la Ciudad de México, llamados Distriubuidor Vial San Antonio y Segundos Pisos del Periférico (2004). Incluímos en esta matriz emergente, las nociones espaciales relacionadas con el ciberespacio, dataespacio y espacio telemático. Del mismo modo inscribimos aquí las constantes de aglomeración de la Ciudad de México que cobran un carácter transitorio aunque “cíclico”, ellas son el tráfico vehicular y la instalación de mercados ambulantes. La vida en el automóvil, lugar literal de tránsito, participa de la contingencia espacio-temporal y es una constante definitoria de la experiencia del espacio y signo de aglomeración recurrente en la Ciudad de México. Circulan más de 3 millones de automóviles diariamente. Se estima que en las horas de más denso tráfico los vehículos avanzan por las principales arterias de la ciudad de México a una velocidad de 13 y 20 kilómetros por hora. Y se instalan temporalmente (por día) 50 mercados ambulantes o tianguis diariamente y aproximadamente 5,000 vendedores ambulantes en el la Zona Metropolitana de la Ciudad de México (2004).

En seguida un modelo de las matrices espacio-temporales o cronotopos, en los que se inscriben los diversos signos arquitectónicos. 


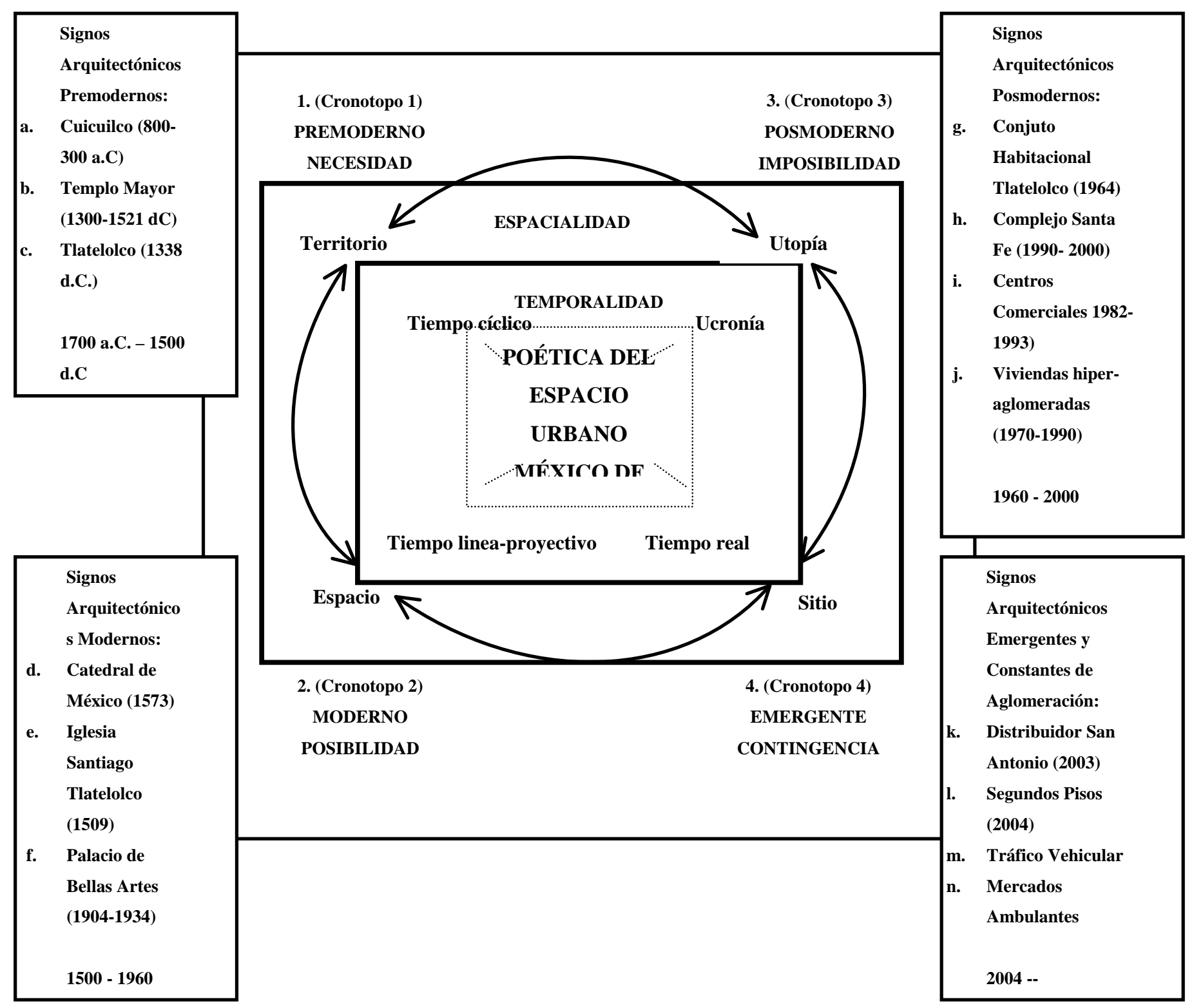

\section{Signos arquitectónicos premodernos, modernos, posmodernos y emergentes en imágenes}




\subsection{Signos arquitectónicos premodernos}

a. Cuicuilco (800 a.C.-300 a.C./ Preclásico)

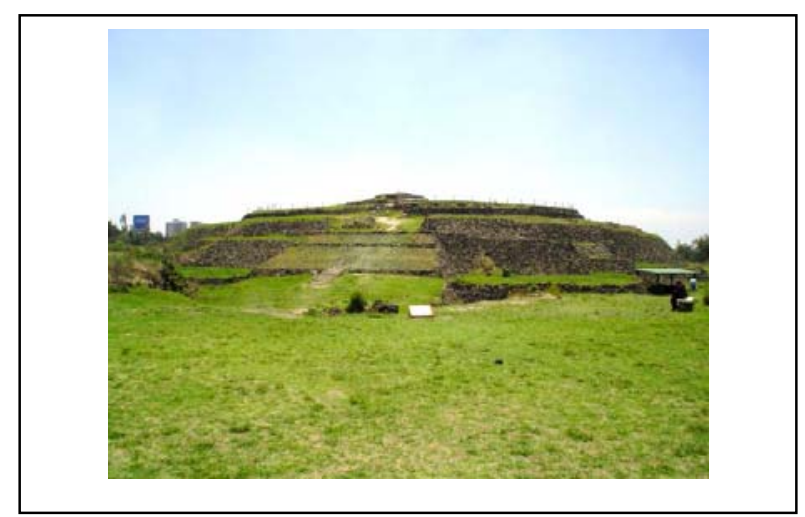

b. Templo Mayor (1300-1521 d.C.)
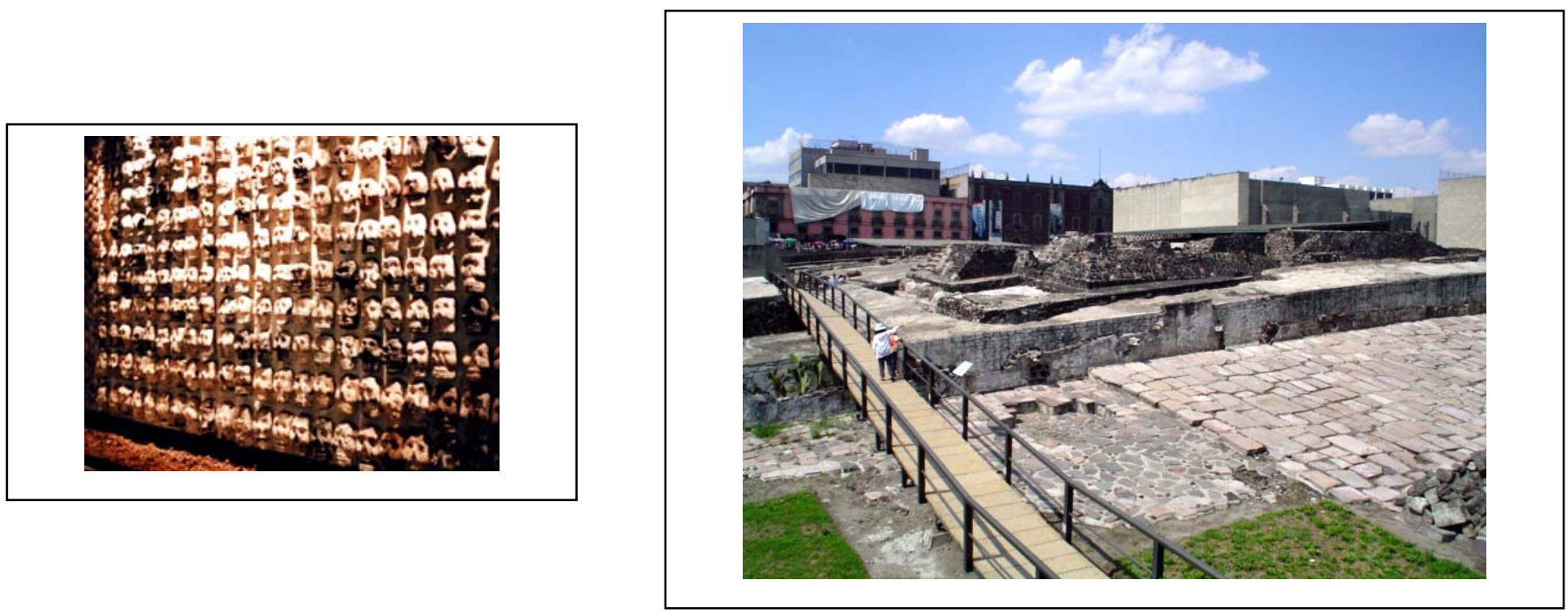

c. Tlatelolco (1338 d.C)

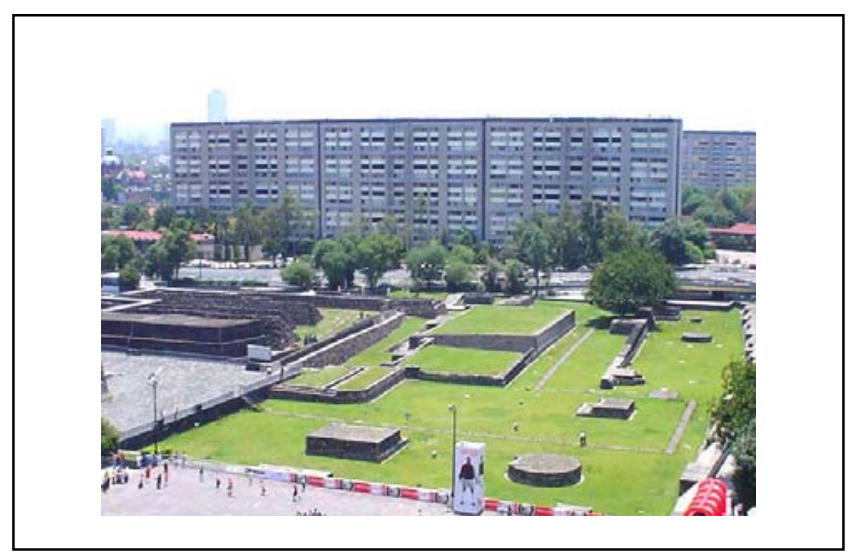




\subsection{Signos arquitectónicos modernos}

d. Catedral de México (1573)
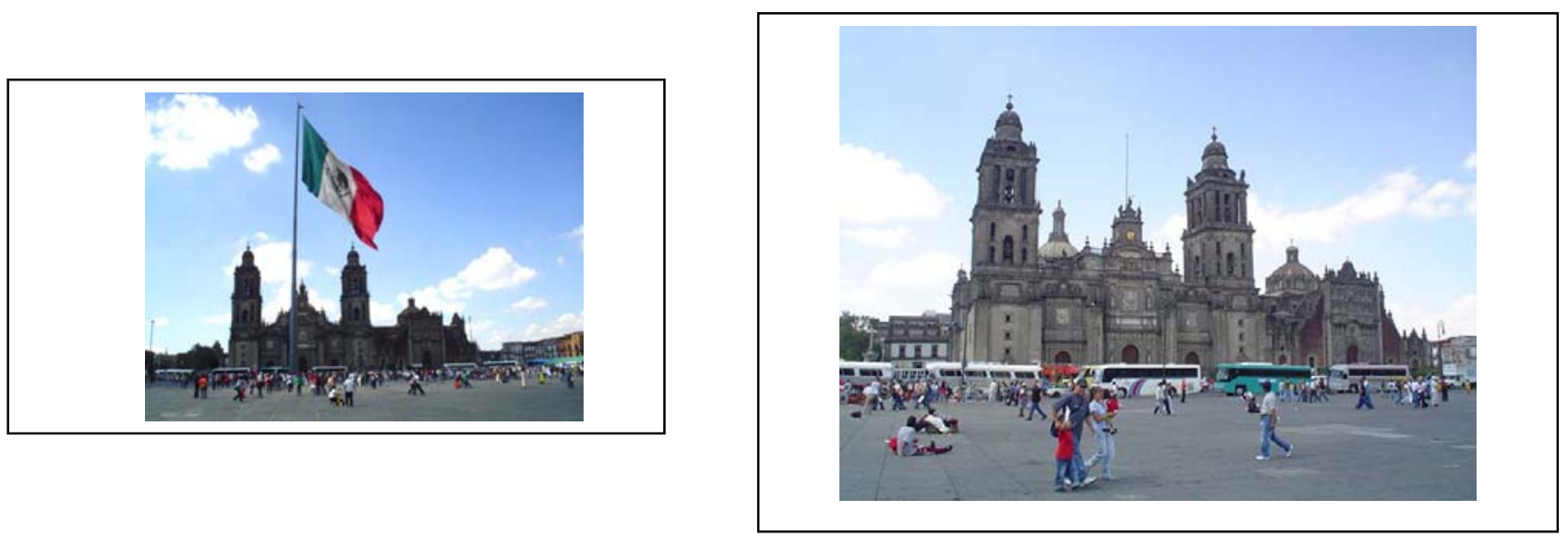

e. Iglesia de Santiago Tlatelolco (1609)
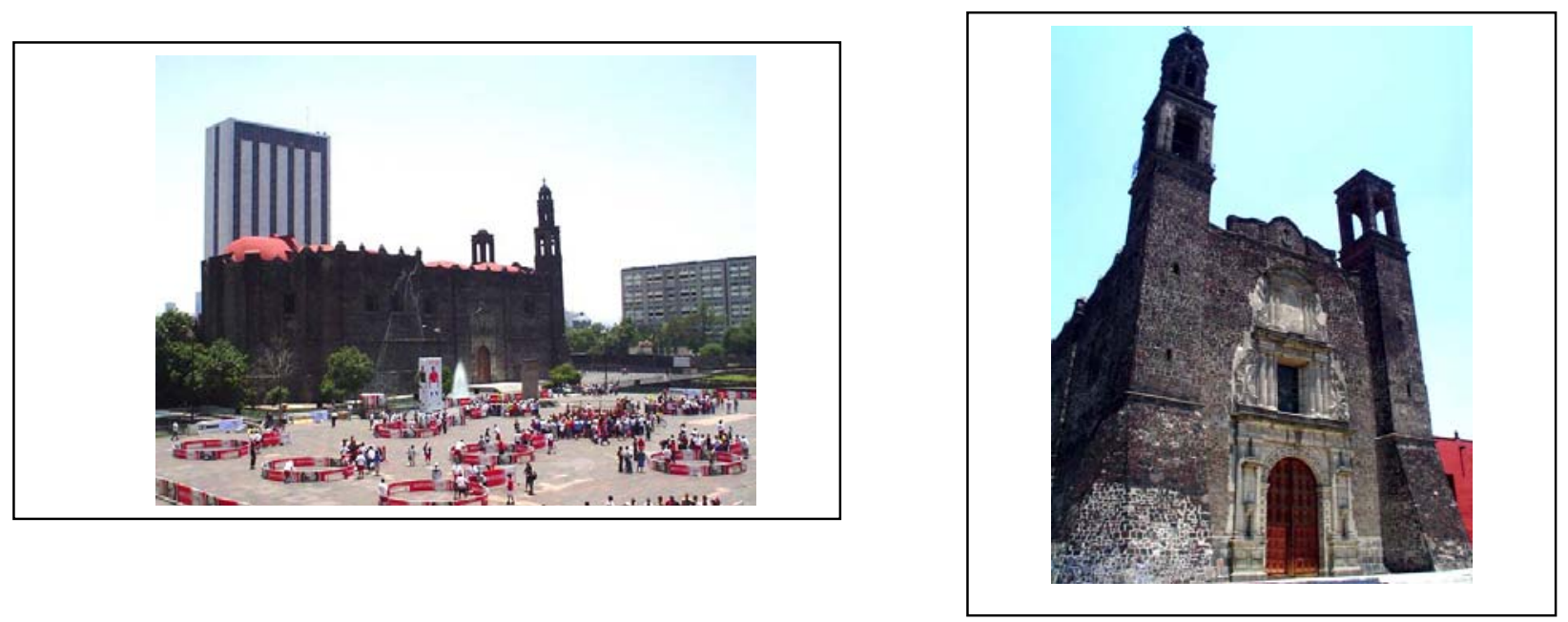

f. Palacio de Bellas Artes (1904-1934)

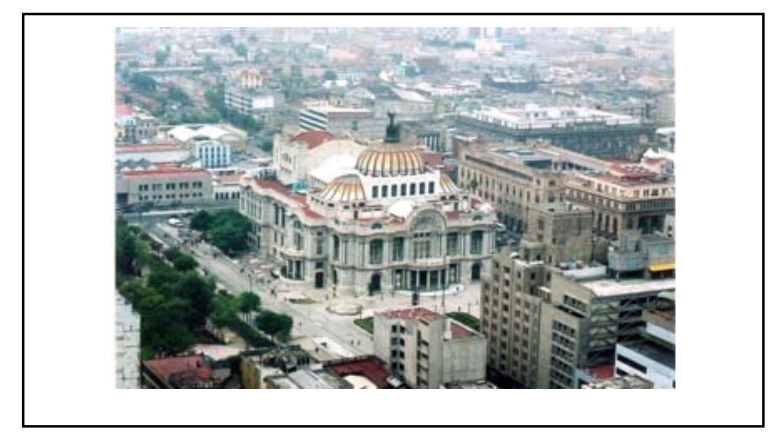




\subsection{Signos arquitectónicos posmodernos}

g. Plaza de las Tres Culturas: Conjunto Habitacional Nonoalco -Tlatelolco (1962-1964)
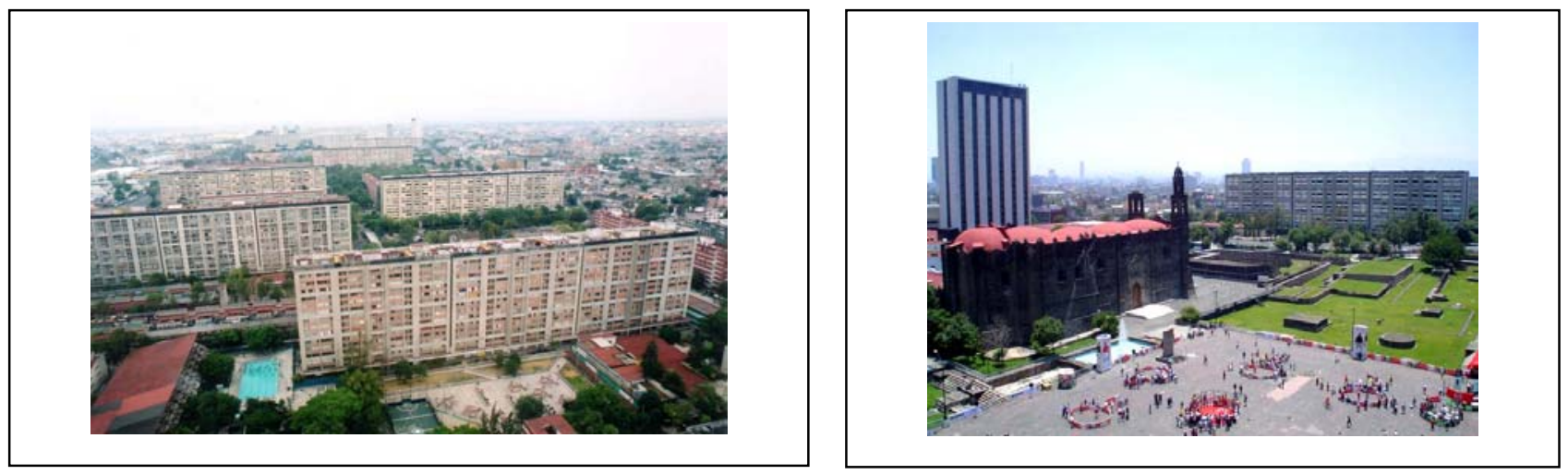

h. Complejo Santa Fe (1990-2004):

1. Corporativo Arcos Bosques, Santa Fe, Ciudad de México.

Arq. Teodoro González de León (1990-1996)
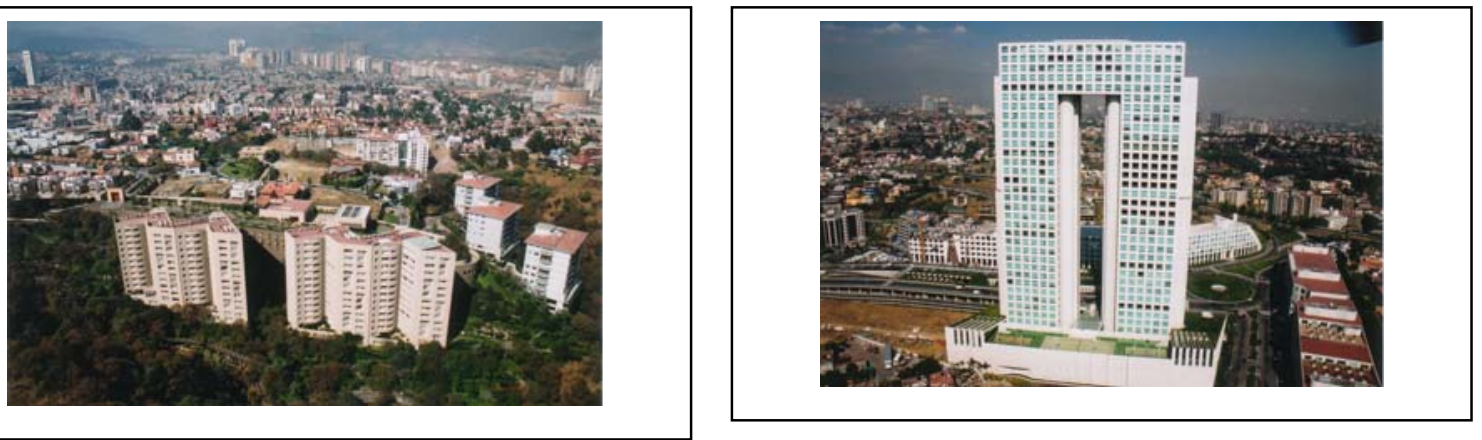

2. Corporativo Calakmul, Santa Fe, Ciudad de

México.Arq. Agustín Hernández. Edificio

Inteligente. Alta Tecnología arquitectónica.

(1994- 1997). 


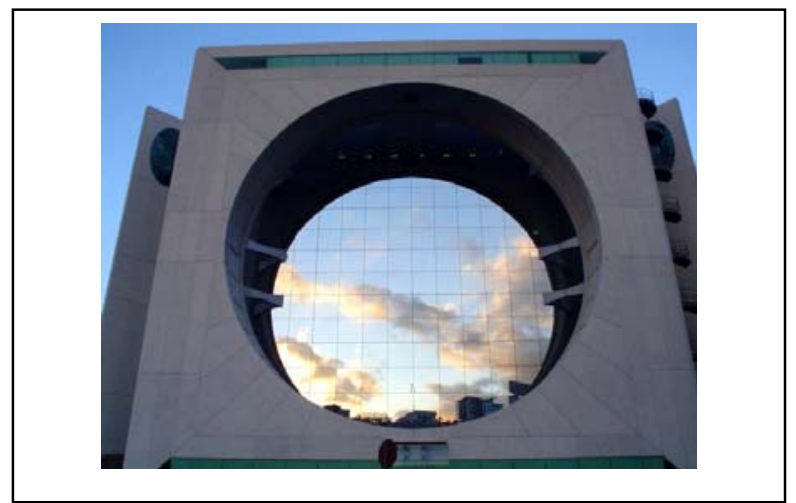

\section{i. Centros Comerciales:}

-Centro comercial Perisur. Arq. Sordo Madaleno (1982)

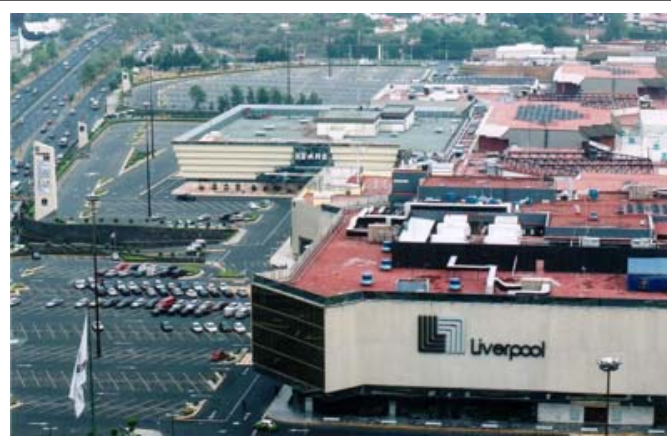

- Centro Comercial Santa Fe (1993)

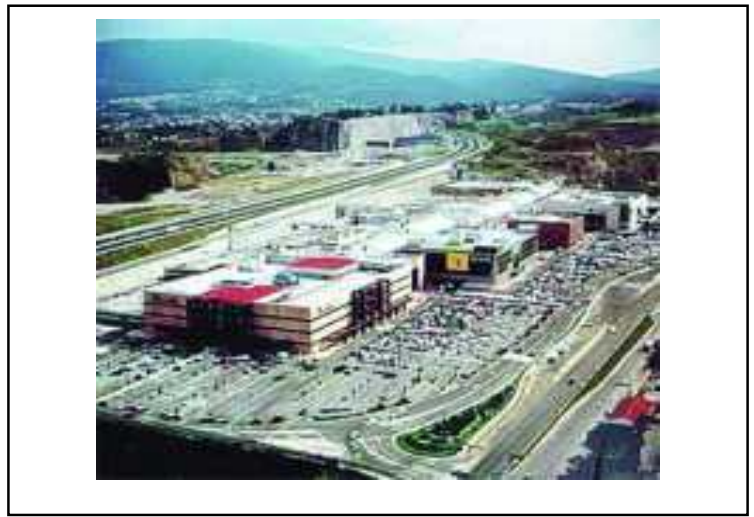


j. Viviendas hiper-aglomeradas Cujimalpa (1970-2000)
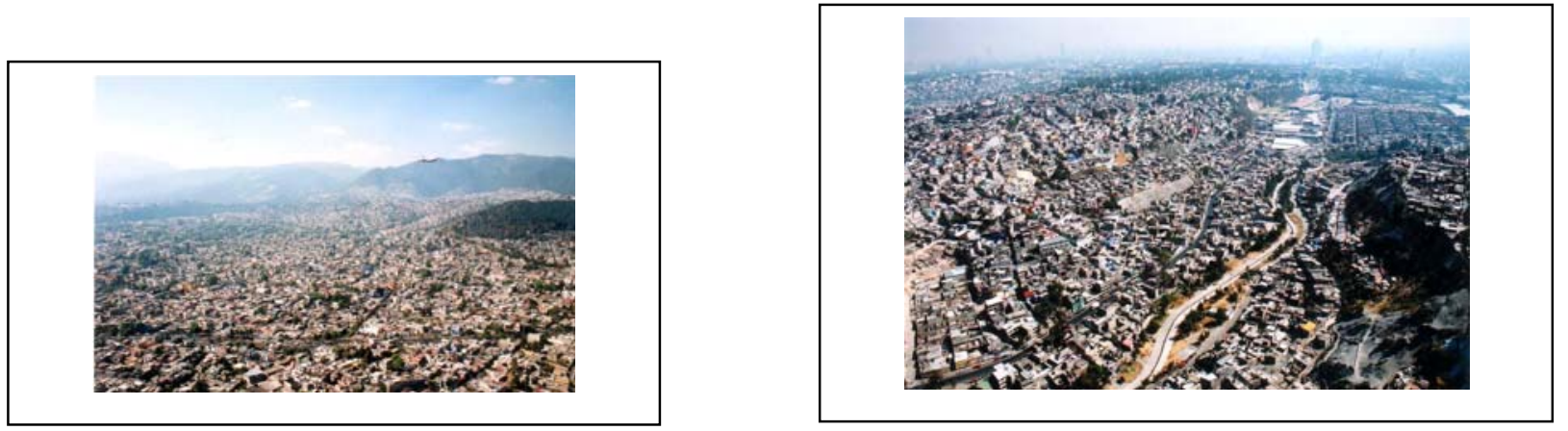

(c) Fotos: Ulises Castellanos

\subsection{Signos arquitectónicos emergentes}

k. Segundos pisos del Periférico y Viaducto (2003)
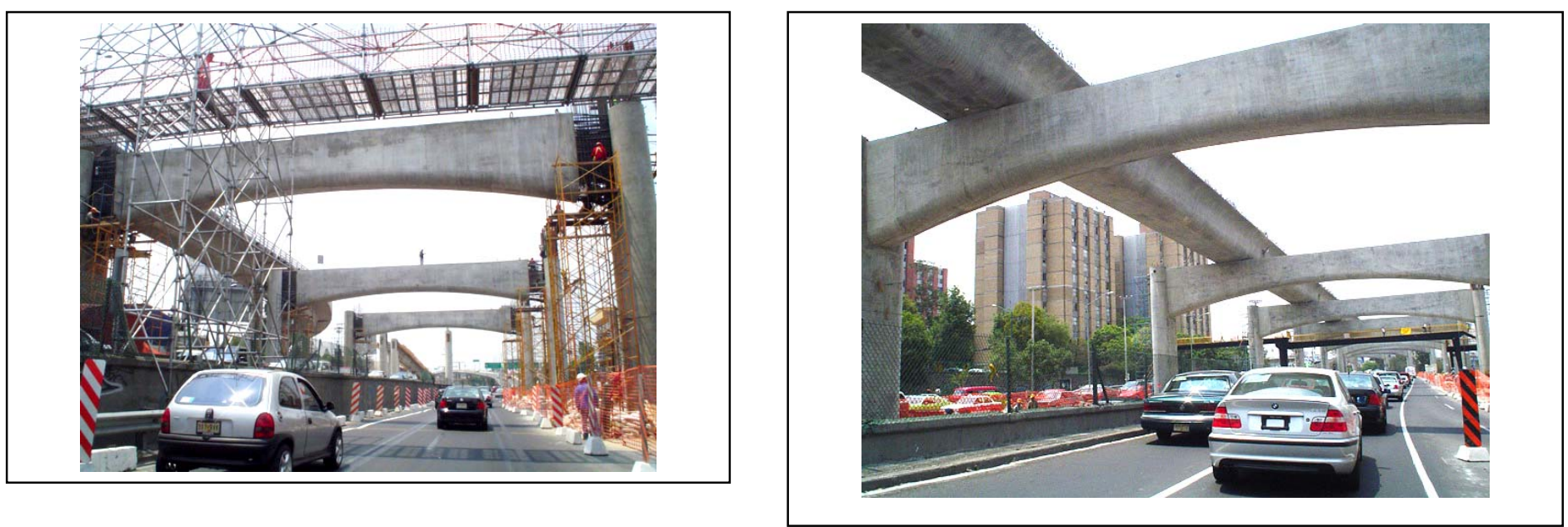

(C) Fotos: Jacob Bañuelos 


\section{Distribuidor Vial San Antonio (2002)}
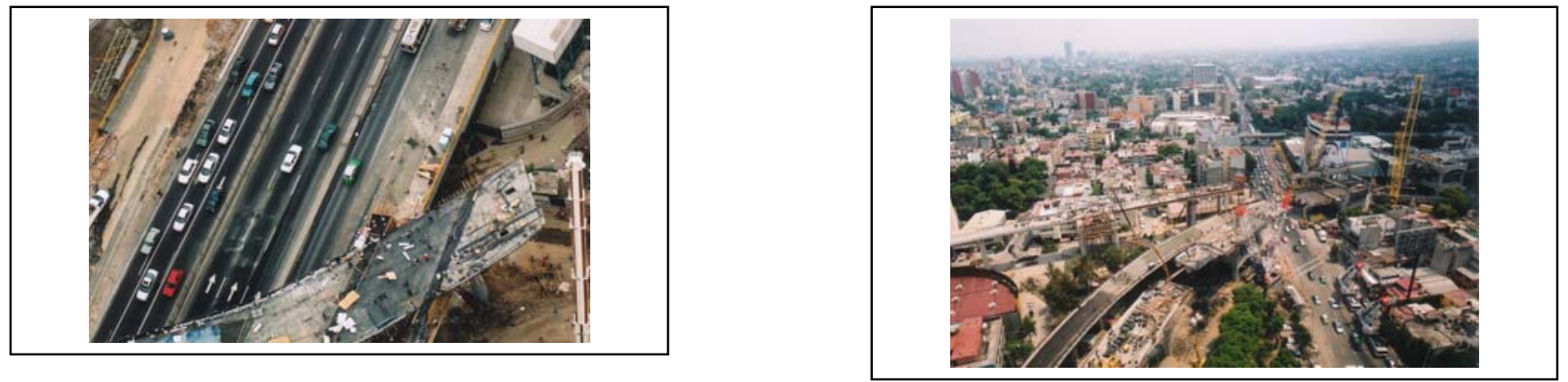

(C) Fotos: Ulises Castellanos
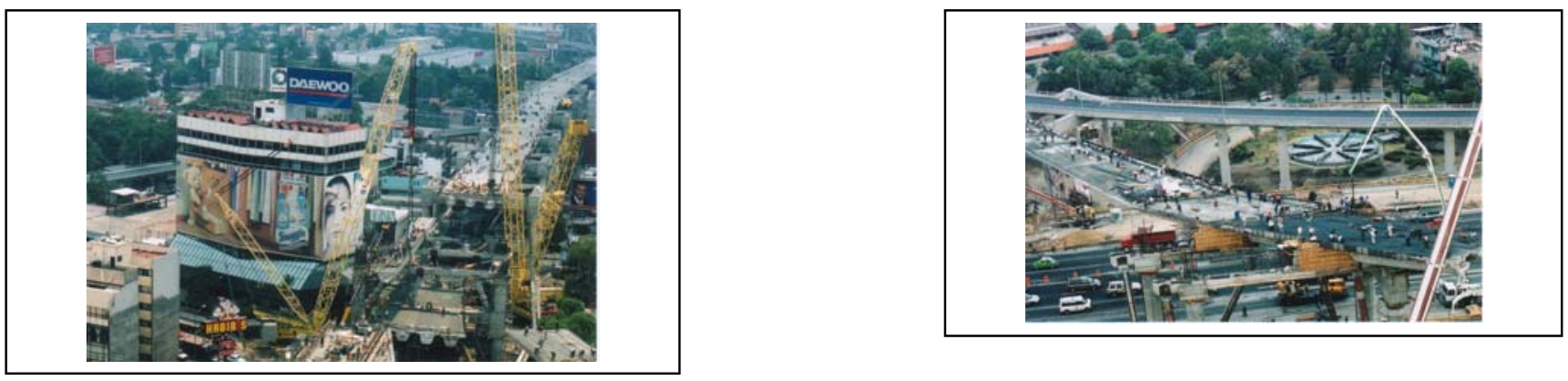

\subsection{Signos urbanos como constantes de aglomeración}

m. Tránsito vehicular. Más de 3 millones de automóviles circulan diaramente (2004)

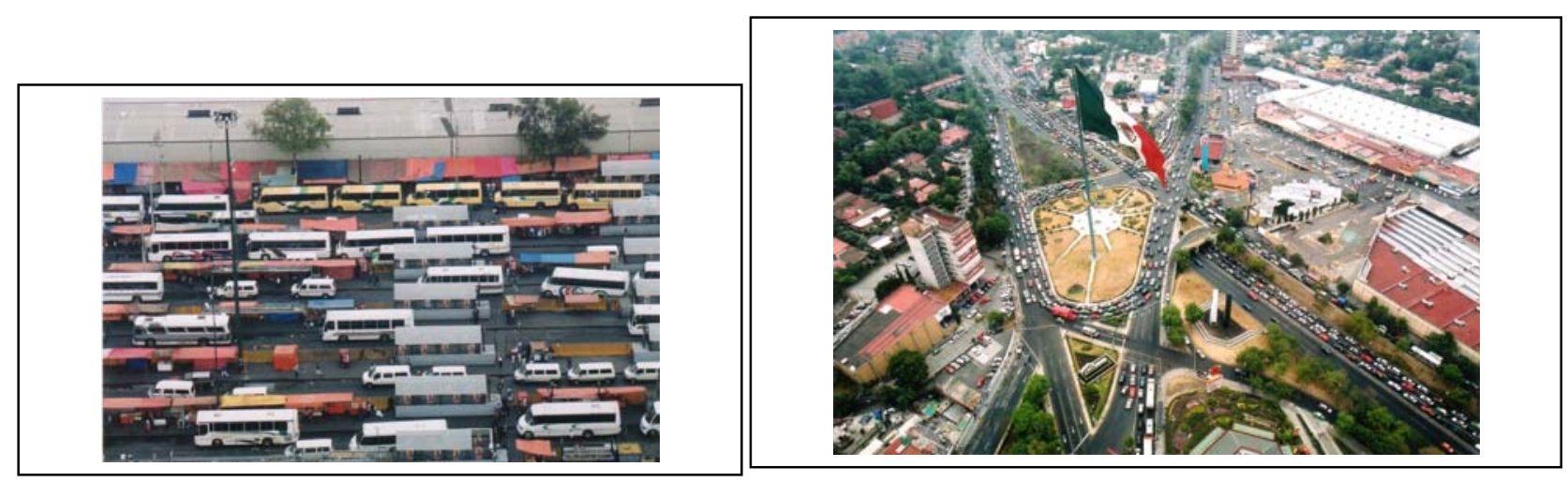



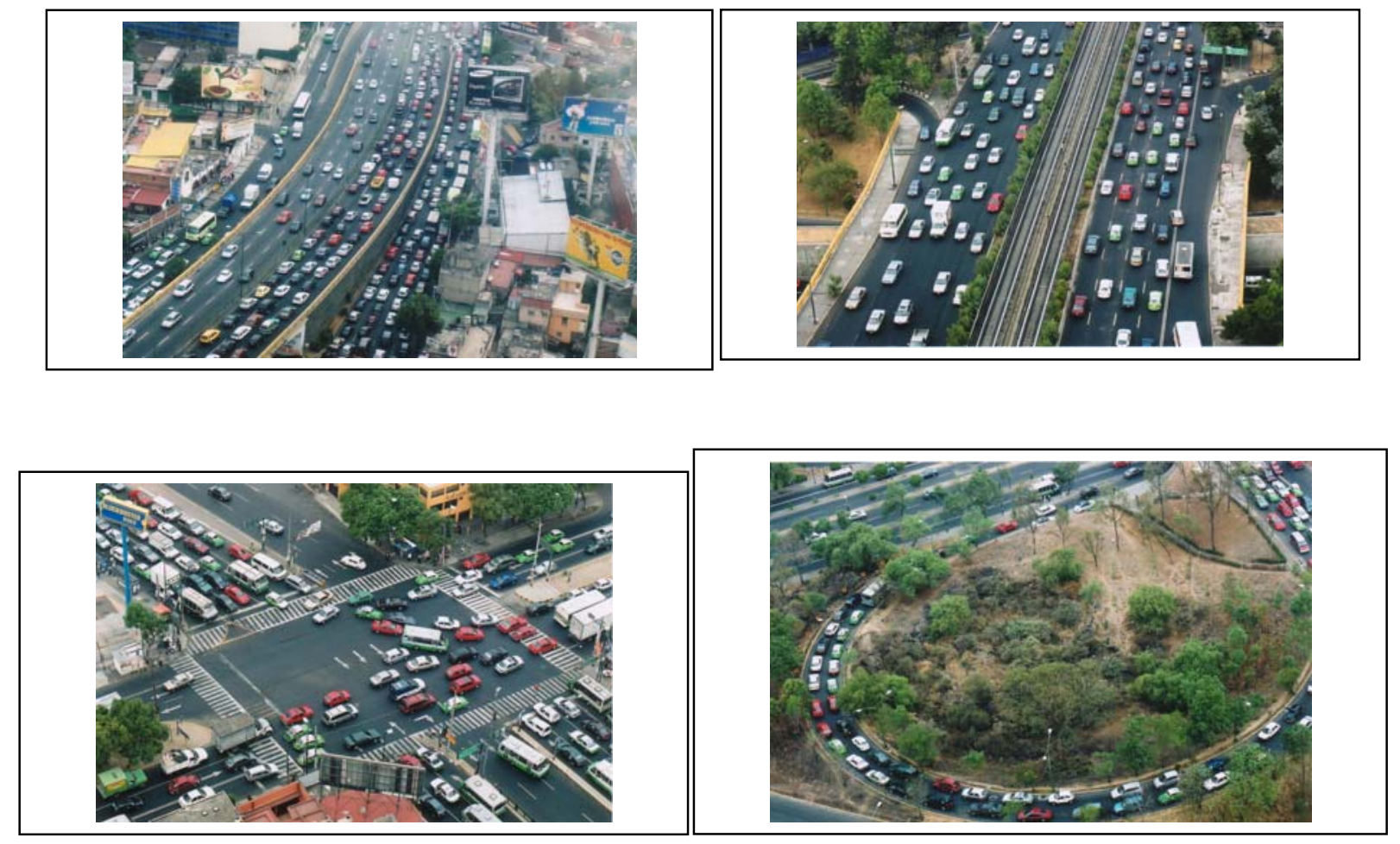

(c) Ulises Castellanos

n. Mercados ambulantes. 50 mercados "tianguis" diarios. Y 5,000 vendedores ambulantes en el la Zona Metropolitana de la Ciudad de México (2004)
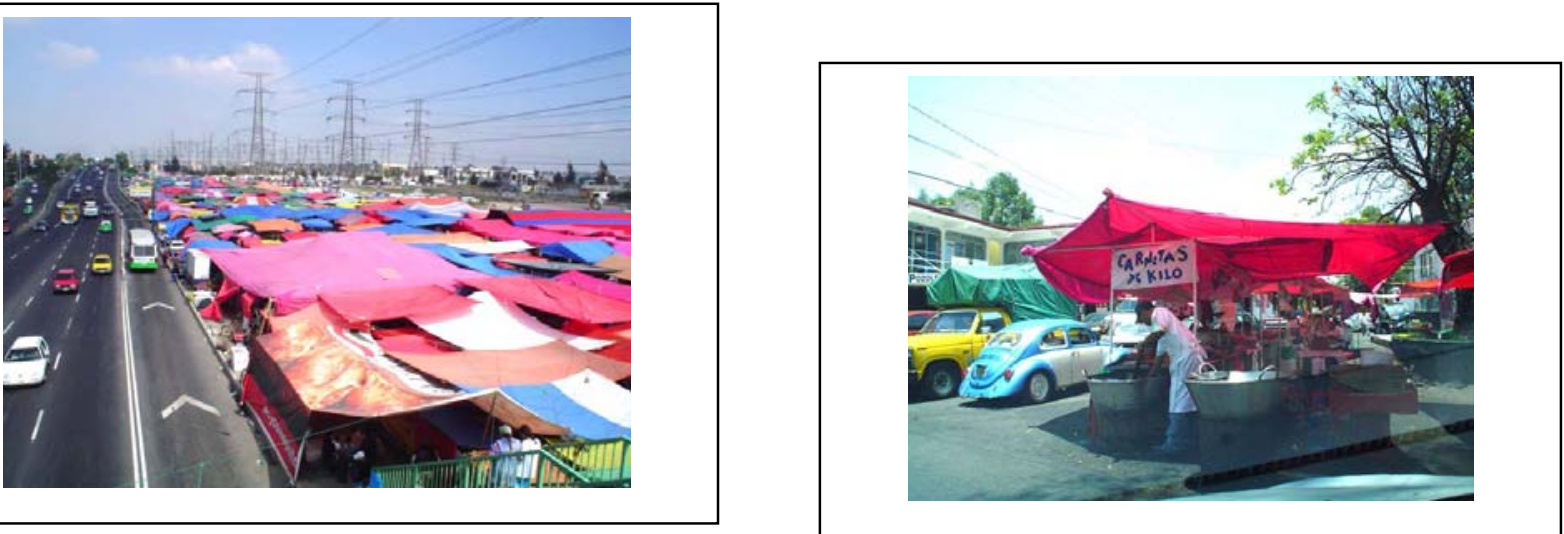

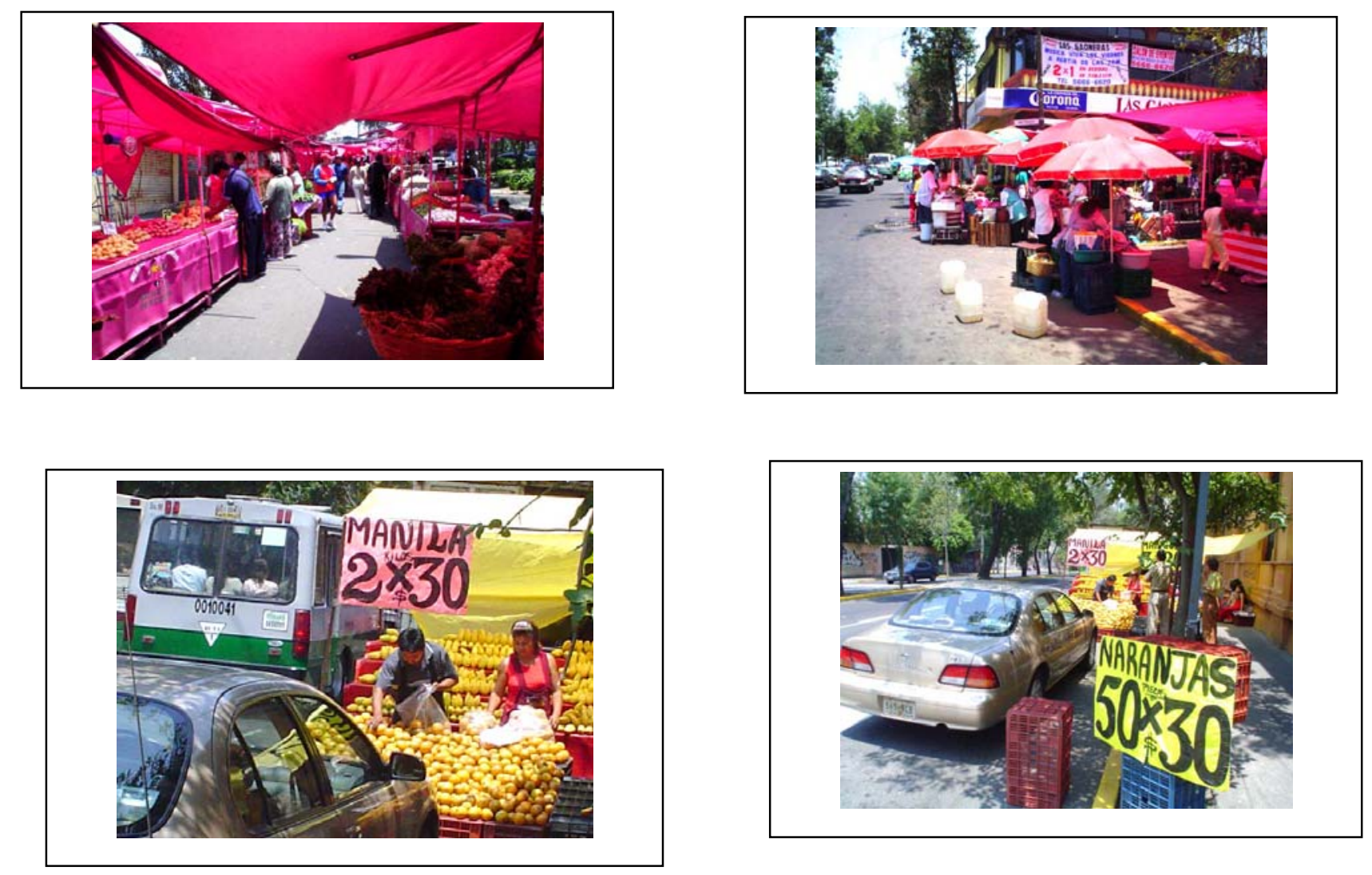

\section{Consideraciones presentes y futuras}

Los signos arquitectónicos del espacio en la Ciudad de México marcan un tránsito histórico que atraviesa desde la premodernidad mexica o azteca (preclásica y postclásica), la modernidad ilustrada heredada del Renacimiento, la posmodernidad heterogénea desde la posguerra (s XX) y las modificaciones emergentes contemporáneas (2004 - s.XXI). Este tránsito histórico marca igualmente relaciones poéticas de tipo dialógico entre los signos arquitectónicos que interaccionan espacial, histórica y culturalmente, sobre todo en la experiencia del sujeto del espacio, el ciudadano.

La poética dialógica del espacio urbano en la Ciudad de México produce una clara estética de la intersección de signos arquitectónicos como orden del espacio y de prácticas culturales del uso del mismo. Vemos así una ciudad aglomerada llena de mercados ambulantes también llamados 
“tianguis", que rompen el orden de una ciudad con exigencias modernas. A esta con-fusión del uso del espacio, entre prácticas premodernas como el mercado ambulante y las construcciones modernas la denominamos posmoderna, incluso como una afirmación de la modernidad. No estamos casados con los conceptos. Nuestra intención es describir la compleja trama de relaciones que presentan los signos arquitectónicos como orden/desorden del espacio urbano en la Ciudad de México, describir sus relaciones poéticas y sus constantes de aglomeración.

El modelo semiótico que aquí presentamos intenta realizar una descripción de signos arquitectónicos clasificados históricamente, inscritos en cronotopos o matrices espacio-temporales que a su vez, corresponden a categorías sociológicas y culturales, como son la premodernizad, modernidad, la posmodernidad y la matriz emergente que delimitamos aquí como parte de los fenómenos de cambio emergente en la sociedad contemporánea.

El Complejo Santa Fe, representa el desarrollo arquitectónico y urbanístico ultra-moderno, en donde se construyen edificios inteligentes (Edificio Calakmul, 1994-1997), centros comerciales y financieros, grandes corporativos empresariales (Corporativo Arcos Bosques, 1990-1996) y que en contraste con el “viejo" Santa Fe, Cuajimalpa, zona de casas populares sin planificación con la que colinda, aparece como una expresión más alta y clara de signos arquitectónicos posmodernos, heterogéneos y contrastantes de la Ciudad de México.

Cabe señalar que las prácticas y los acondicionamientos arquitectónicos dispuestos para la vida telemática y el funcionamiento del ciberespacio han quedado dentro de la matriz de contingencia, es decir, dentro de la matriz sitio-momento emergente. Los signos emergentes de esta matriz serían las antenas parabólicas y nodos que construyen dicho espacio telemático, así como todos los puestos informacionales o informáticos que se construyen para las prácticas del uso del ciberespacio: kioskos de internet, cibercafés, y frecuentemente lugares transitorios como puestos informáticos de internet.

Vemos el espacio urbano de la Ciudad de México como un modelo de relaciones dialógicas de oposición de las cuales surgen nuevos significados, nuevos signos y usos nuevos espaciales. La Ciudad de México es una mega-ciudad, resultado de una suma histórica de pueblos pequeños que se incorporaron progresivamente y sin planificación a la gran masa urbana que es hoy. Por ello, muchos municipios conservan todavía estructuras urbanas moderno-ilustradas, como la estructura del zocalo, iglesia, ayuntamiento, mercado. Así como las estructuras de las prácticas culturales tradicionales de tipo religioso o pagano.

Una práctica imperante en la Ciudad de México es la venta ambulante y la instalación cíclica por un día de mercados ambulantes en diversas zonas de la ciudad. Esto convierte por momentos a la 
ciudad en una especie de gran mercado, en donde se puede comprar en vías públicas, en calles vehiculares e incluso en vías de alta velocidad. Esta experiencia del uso tradicional del mercado en medio de la gran ciudad moderna, marca una desviación poética más de esta gran Ciudad.

A pesar de los mercados ambulantes y tianguis del D.F., la práctica de caminar en la ciudad choca progresivamente con las dimensiones y estructura que la misma proporciona al ciudadano, atrapado en una red de tráfico vehicular y en la insuficiencia del transporte público. Caminar choca con el proyecto moderno planteado en la Ciudad de México, a pesar de las plazas históricas coloniales que todavía conservan su espíritu como Coyoacán, la Alameda, el Zócalo, y el centro de Tlalpan, convertidos igualmente en mercados o tianguis y que los fines de semana participan del efecto de saturación y aglomeración constantes de la ciudad.

El significado del espacio depende del sujeto que lo experimenta, es simbólico, cultural y funcional. Cada ciudadano hace de la ciudad una lectura diferente. La semántica del espacio en la Ciudad de México es una compleja trama de referencias históricas, biográficas y emocionales. Interpretamos los cronotopos como matrices culturales que dan sentido semántico histórico a las concepciones que han dado y dan origen a los signos arquitectónicos de la Ciudad. Esto será un trabajo que invitamos a abordar en colaboración.

El diálogo poético espacial en la Ciudad de México, efectivamente hace, como apunta Yates, que los conceptos históricos de distancia, medida o escala se relativicen y transformen. Y la historia, la cultura y la ficción entran en un campo dinámico de experiencias diversas en marco de la Ciudad. Remarcamos que los espacios son siempre culturales y simbólicos. Por lo que queda pendiente una profundización en el análisis de los valores simbólicos y culturales de los signos arquitectónicos del espacio en la Ciudad.

Siguiendo a Yates, la transformación del significado del espacio indica un cambio fundamental en la cultura. En la Ciudad de México, el colapso es el resultado final intermitente de la aglomeración espacial. En algún momento hemos guardado la esperanza de que en medio del caos se conserve el orden. Echamos la mirada hacia el futuro de la Ciudad de México y la mayoría de nosotros tiene una visión apocalíptica. Sin embargo, han pasado ya casi 40 años de este próximo Apocalipsis y todavía aguanta un poco más el espacio de la Ciudad antes de colapsarse del todo. ¿Cuántos años más aguantará?

Nuestro estudio final, pretende crear un modelo semiótico descriptivo que enuncie las problemáticas constantes y relevantes de la Ciudad de México, con el fin de comprender, visualizar y 
conceptulizar la solución de problemáticas que tienden a convertir a la Ciudad en un espacio inhabitable, para lo que esto es sólo un apunte inicial.

La Ciudad de México es “plana”, extensa y superpoblada, es resultado de la negación a planificar y ordenar ecológicamente el espacio, está rodeada por un sistema orográfico y en su origen era un lago y una suma de isletas, más parecido a las ciudades holandesas y Países Bajos, en donde sí se han conservado los canales que articulan las ciudades.

Actualmente la Ciudad de México se extiende ya hacia las montañas que la rodean. Al carecer de más espacio, se han comenzado a construir grandes rascacielos y es previsible que esta sea la tendencia en un futuro. Sin olvidar, que históricamente la ciudad está ubicada en una zona sismológica y que su recarga natural de mantos acuíferos es del 59.1\%, lo que ha impedido durante mucho tiempo realizar grandes elevaciones arquitectónicas, y que gracias a los avances en ingeniería y arquitectura estos impedimentos se han ido dejando atrás.

Quede así el presente análisis como un apunte teórico a desarrollar más profundamente en el futuro cercano. Nuestra experiencia de aglomeración cotidiana en la Ciudad de México no deja de ir acompañada de una grata mezcla de relaciones poéticas que de lugar en lugar nos recuerdan que todavía es un espacio humano y habitable. Nuestro deseo: que la emergencia contemporánea sea sustentable para conservar y aliviar los graves problemas de hacinamiento, desigualdad socioeconómica, hiper-aglomeración de población, vivienda, tráfico, colapso y saturación del espacio a la que llega la Ciudad de México en los albores de este s. XXI.

Jacob Bañuelos Capistrán.

Todas las fotografías aéreas de esta investigación son autoría de Ulises Castellanos, Editor Jefe Fotografía, Revista Proceso, México D.F, a quien damos un agradecimiento especial por brindar este valioso material fotográfico. El resto del material fotográfico ha sido realizado por el autor de esta investigación, Jacob Bañuelos.

\section{NOTAS}

1. Yates, S. (2002: 20).

2. Paz. O. (1986:108)

3. Beristain H. (2001: 233) 
4. Greimas y Courtés (1973: 153-171).

5. Abril (1997: 181).

\section{BIBLIOGRAFÍA}

ABRIL, G., 1997: Teoría general de la información, Madrid, Cátedra.

ABBAGNANO, N., 1986: Diccionario de filosofía, México, FCE.

BAJTIN. M., 1989: Teoría y estética de la novela, Madrid, Taurus.

BERISTAIN, H., 1992: Diccionario de poética y retórica, México, Porrúa.

BETTETINI, G. y COLOMBO, 1995: Las nuevas tecnologías de la comunicación, Barcelona, Paidós.

DE LAS HERAS, R., 1991: Navegar por la información, Madrid, Fundesco. Se han retomado sólo algunos elementos de cuadro propuesto por De las Heras, ya que el autor propone un cuadro de soportes de información más amplio.

GREIMAS A.J.; COURTES, J. , 1982: Semiótica. Diccionario razonado de la teoría del lenguaje, Madrid, Gredos.

JANOKOVSKI, N.W. (eds.), 1993: en Teoría general de la información, Madrid, Cátedra, (págs. 211-228), citado por Abril, G. (1997, p. 171),

LÉVY, P. , 1998: ¿Qué es lo virtual?, Barcelona, Paidós.

PAZOS, L., 2001: Historia sinóptica de México. De los olmecas a Fox, México, Diana.

PAZ, O., 1986: El arco y la lira, $1^{\text {a }}$ ed. México, FCE.

SHUDSON, M., 1993: “Enfoques históricos a los estudios de la comunicación, en Jensen, K.B.

TAMAYO, Sergio. WILDNER, K., 2000: Lugares de globalización: una comprensión arquitectónica $y$ etnográfica de la Ciudad de México. http://www.memoria.com.mx/156/Tamayo.htm

YATES, S., 2002: Poéticas del espacio: antología crítica sobre fotografía, Barcelona, Gustavo Gili. WARD, Peter., 1991. México megaciudad: desarrollo y políica, México, Porrúa-El Colegio Mexiquense.

\section{Referencias en Internet}

Cronología de México. Historia. http://www.arts-history.mx/cronos/1.html

http://www.mexicocity.com.mx/historia1.html\#Fundaci-n 
http://www.bancomext.gob.mx/esp/olivera.html

http://www.mexicocity.com.mx/crecer.html

http://www.cuentocontigo.gob.mx/secciones/secconomex/estados/mapas_municipios_pdf/DF_MUN. pdf

\section{REFERENCIAS ADICIONALES RECOMENDADAS}

Alarcón González, Sandra (2000), "El tianguis global", en Bueno, Carmen, Globalización: una cuestión antropológica, CIESAS, México.

Appadurai, A (Ed.) (1989), The social life of things: commodities in cultural pespective, Cambridge Press, New York.

Beauregard, Robert y Anne Haila (2000), "The unavoidable continuities of the City", en Marcuse, Peter y Ronald van Kempen (ed.) Globalizing Cities. A new spatial Order? Oxford, Blackwell Publishers.

Bueno Castellanos, Carmen (coord.) (2000), Globalización: una cuestión antropológica, CIESAS, México.

Celyk, Zeynel (1998), "Intersecciones culturales: reorientando la arquitectura y la ciudad en el siglo XX", en Richard Koshalek y Elizabeth A.T. Smith (comp.), A fin de siglo, cien años de arquitectura, México: El Antiguo Colegio de San Ildefonso y The Museum of Contemporary Art, Los Ángeles.

Coombe R.J. (1995), "The cultural life of things: globalization and anthropological approaches to commodification", American Journal for International Law Politics 10 (1).

De Certeau, M. (1996), La invención de lo cotidiano, I. Artes de hacer, Universidad Iberoamericana, Instituto Tecnológico y Estudios Superiores de Occidente y Centro Francés de Estudios Mexicanos y Centroamericanos, México.

Eade, John (Ed.) (1997), Living the global City, Globalization as a local process, Routledge Londo, New York.

Featherstone, Mike (1989), Undoing Culture, Globalizacion, Postmodernism and Identity, Routledge, London et.al.

García Canlini, Nestor (1989), "La desintegración de la ciudad de México y el debate sobre culturas urbanas", en García Canclini (coord.), De lo local a lo global, Perspectivas desde la antropología, UAM-I, México. 
---- (1999/2000), La globalización imaginada, Editorial Paidós Mexicana, México.

Gottdiener, Marc (1995), Postmodern Semiotics, Material Culture a the Forms of Postmodern Life, Cambridge, Blackwell Publications.

Gupta, Akhil y Yames Ferguson (1992), "Beyond Culture: Space, Identity, and the Politics of Difference", en Cultural Anthropology 7: 6-23

Herzog, Lawrence (1999), From Aztec to High Tech. Arquitecture and Landscape across the México-United States Border, Balitmore, John Hopkins University Press.

Ingersoll, Richard (1996), Un reproche silencioso: observaciones sobre la arquitectura mexicana reciente,en Adriá, Miguel (Ed.) México 90’s - Arquitectura contemporánea, México.

Koolhaas, Rem y Bruce Mau (1989), S,M,L,XL, New York.

LCM - Laboratorio de la Ciudad de México (1999) ZMCM, México.

Maldonado, Julieta (1996) "Edificios Corporativos", en Enlace Jg. 6, N.10, Octubre.

MARCUS, George (1995), "Ethnography in/of the World System- The Emergence of Multi-Sited Ethnography", en Annual Review of Anthropology 24;.95-117

Marcuse, Peter y Ronald van Kempen (ed.) (2000), Globalizing Cities, A new spatial Order? Oxford, Blackwell Publishers.

Parnreiter, Christof (1998) La ciudad de México, ¿una ciudad global? en Anuario de Estudios urbanos, 1998, Universidad Autónoma Metropolitana, Azcapotzalco, México.

--- (2000), "Mexico City: The Making of a Global City?" en Saskia Sassen (ed), Cities in Their Crossborder Networks, Tokyo, UNU-Press.

--- (2000b), "Globalization, Transformation and Urban Primacy: Towards More Balanced Systems of Cities? Lessons from Latin America with particular emphasis on Mexico", Paper en Conference of the International Geographical Union - The Commission on Urban Development and Urban Life, August 9 to 13, 2000 in Seoul, Korea.

Rogers, Aldair (1988), "The Ghetto and the Barrio: A Social Geography of Blacks and Latinos in Los Angeles", Oxford: unpublished PhD thesis, University of Oxford, 1988.

--- (1995) Cinco de Mayo and 15 January: Contrasting Situations in a Mixed Ethnic Neighbourhood, en Rogers, Alisdair/Vertovec, Steven (ed.) The Urban Context - Ethnicity, Social Networks and Situational Analysis, Oxford University Press, Oxford.

Sassen, Saskia (1991), The global City. New York, London, Tokyo, Princeton University Press, Princeton.

Tamayo, Sergio (2001), "Archipiélagos de la modernidad urbana, Arquitecturas de la globalización 
en la Ciudad de México", en Anuarios de Espacios Urbanos, 2001, Universidad Autónoma Metropolitana, Azcapotzalco, México.

--- (1999), Los veinte octubres mexicanos, Ciudadanías e identidades colectivas, Universidad Autónoma Metropolitana, Azcapotzalco, México.

Terrazas, Oscar (2000), Centrality and Globalization in México City, Paper presentado en LASA, Conferencia, Miami, 2000.

Tomas, Francois (1994), "Estrategias socio-espaciales", en Revista Mexicana de Sociología, 4/94. Vargas Cetina, Gabriela y Steffan Igor Ayora-Diaz (1994), "Introduction. Local Expresion of Global Culture: Four Case Studies from Mexico", en Urban Anthropology and Studies of Cultural System and World Economic Development. Vol.27, No. 2: 123-135.

Vargas Cetina, Gabriela (2000) "Cooperativas y Globalización, El movimiento cooperativo internacional localizado", en Bueno, Carmen, Globalización: una cuestión antropológica, CIESAS, México.

Wildner, Kathrin (1998), "El zócalo de la ciudad de México, un acercamiento metodológico a la etnografía de una plaza", en Anuario de Estudios Urbanos, 1998, Universidad Autónoma Metropolitana, Azcapotzalco, México.

--- (2000) Zócalo - Etnografie eines Platzes in Mexiko Stadt, en Hengartner, Thomas; Kokot, Waltraud y Wildner, Kathrin (coord), Kulturwissenschaftliche Stadtforschung, Eine interdisziplinäre Bestandsaufnahme, Dietrich Reimer Verlag, Berlin.

\section{CUADROS}

1. Cuadro semiótico de modalidades aléticas, (Greimas y Courtés, 1982: 31)

2. MODELO SINTAGMÁTICO DE MATRICES ESPACIO-TEMPORALES Y CIRCUITO DEL SIGNO ARQUITECTÓNICO QUE DESCIRBE LA POÉTICA DEL ESPACIO EN LA CIUDAD DE MÉXICO CONTEMPORÁNEO (2004). 


\section{ANEXO}

Templo Mayor. 1325 d.C. Fecha más aceptada para la fundación de México-

Tenochtitlan.**Fundación de México-Tenochtitlan: la migración de los mexicas termina al llegar al islote donde identifican los símbolos de la tierra prometida, que correspondían además a la descripción del lugar de origen abandonado. El círculo de su historia se cierra y comienza una nueva era, la de sedentarización definitiva. Se ha argumentado que los mexicas escogieron el lugar deliberadamente por las ventajas que ofrecía, debido a su localización estratégica y su potencial de explotación lacustre. El lugar fue nombrado México-Tenochtitlan; capital azteca situada sobre un islote en la parte pantanosa del Lago de Tezcoco, en el Valle de México. La ciudad creció rápidamente en tamaño e importancia al ir los aztecas ganando supremacía en el centro de México. Tenochtitlan estaba dividida en cuatro distritos principales con el recinto ceremonial principal al centro. . (fuente: http://www.arts-history.mx/cronos/1.html)

Tlatelolco. Tlatelolco fue el centro comercial más importante del México prehispánico y lo que se sabe es que después de fundada Tenochtitlan (en 1325), Huitzilopochtli ordenó a los mexicas que se repartieran sobre los cuatro ámbitos del mundo, por lo que Tenochtitlan de acuerdo con la primera lámina del Códice Mendocino quedó dividida en 4 grandes sectores, cuyos nombres eran Cuepopan, Moyotlan, Zoquiapan y Atzacualco. Sin embargo una vez que quedó concertada la división de la ciudad, para el año 1337, un grupo que no se sentía conforme con los terrenos adjudicados decidió buscar otro sitio y se asentaron entre el lago y los carrizales, en una terraza (tlatelli) o un xaltilolli, punto "arenoso" palabras de las cuales proviene el nombre de Tlatelolco con el que se identificaron. Otras fuentes dicen que los tlatelolcas llegaron directamente a fundar ese sitio, sin haber estado antes en Tenochtitlan. Independientemente de que Tlatelolco haya sido fundado antes o después de Tenochtitlan, ambos nacen y comparten el mismo destino. Los tenochcas o mexicas controlaron el poder ideológico, político y económico; los tlatelolcas dirigieron el comercio. En 1428 luego de la liberación del señorío de Azcapotzalco, los mexicas se reorganizaron para trasladar el mercado de Tenochtitlan a Tlatelolco, ello originó el tianguis más importante del México prehispánico. Los mexicas, aun después de dividirse el poder, continuaron con sus diferencias, las cuales culminaron en una guerra en 1473. Axayacatl, gobernante tenochca, subordinó al pueblo tlatelolca. En 1515 Cuauhtémoc fue elegido gobernante de Tlatelolco. A la llegada de los conquistadores españoles, Moctezuma Xocoyotzin gobernaba Tenochtitlan; tras la muerte de éste, los mexicas eligieron a Cuauhtémoc señor de las dos ciudades y combatió contra los hispanos hasta que fue sitiado en esa ciudad, cuyos habitantes resistieron durante 80 días, al final de éstos Cuauhtémoc cayó prisionero. El 
13 de agosto de 1521 fue finalmente capturado por Diego de Holguín. La caída de Tlatelolco marcó el fin del más importante Imperio mesoamericano. La colaboración de los pueblos hasta entonces sometidos a la hegemonía azteca facilitó la expansión de la empresa conquistadora. Enseguida se muestra la placa que conmemora la caída de Tlatelolco en la explanada de la actual Plaza de las tres Culturas

\section{(Fuente: Miniguía editada por el INAH)}

Cuicuilco. *ca. 1700 a.C. La región en donde posteriormente florecería la ciudad de Cuicuilco, para estos años, estaba conformada por pequeños conglomerados humanos, que poco a poco se fueron transformando en aldeas de chozas, agrupadas alrededor de un centro religioso. Al hacerse más compleja la sociedad, la casta sacerdotal logró integrar un gobierno teocrático, con una religión oficial que necesitaba grandes centros ceremoniales que sirvieran tanto para la celebración de las festividades como para congregar a la población dispersa en áreas rurales. Así, los minúsculos recintos rituales aumentaron su tamaño hasta conformar una verdadera unidad religiosa con arquitectura monumental. Cuicuilco: se localiza al suroeste del Valle de México. Hacia el 300 a.C. se conforma casi como centro urbano debido a su crecimiento tanto poblacional como constructivo, aun así, poco después fue eclipsado por Teotihucán y empezó a decaer. Por otra parte se cree que su decadencia fue una consecuencia directa de las erupciones volcánicas que cubrieron con lava las tierras agrícolas cercanas. *ca. 800 a.C. Cuicuilco presenta un crecimiento en tamaño y población.. *300 a.C. Para esta fecha es probable que Cuicuilco fuera el centro más grande en el Valle de México. *200 al 100 a.C. Decadencia de Cuicuilco. *100 a.C. Desaparición catastrófica de Cuicuilco. (fuente: http://www.arts-history.mx/cronos/1.html)

En opinión de Zelia Nuttall, significa: “Lugar donde se hacen cantos y danzas”. El sitio se ubica en el suroeste de la cuenca de México en un antiguo delta del río formado por las corrientes que bajaban del Zacatépetl y el actual bosque de Tlalpan. Se afirma que el desarrollo del lugar, desde época temprana, se debe a su posición estratégica, ya que el occidente de la cuenca se conecta con la entrada al valle de Toluca. Asimismo, se considera que el declive de Cuicuilco se generó entre 100 a.C.-1 d.C., y aunque hubo una ligera recuperación durante 1-150 d.C., la presencia de deidades del fuego, y ceniza volcánica en los pisos, sugiere fuerte actividad volcánica en la cuenca de México. No obstante el abandono de Cuicuilco como gran centro ceremonial, se continuó haciendo ofrendas hasta el momento en que la localidad fue cubierta por las lavas del Xitle, lo que ocurrió alrededor del año 400 después de Cristo. Desde principios de este siglo El Pedregal fue un lugar atractivo para definir las culturas antecesoras a las formaciones socioeconómicas teotihuacana y mexica en la 
cuenca de México. Las investigaciones en Cuicuilco B demostraron que el desarrollo del sitio es producto de una dinámica interna. Bajo esta perspectiva, aunque el lugar era productor, hacia 600200 a.C., de una nueva tradición cerámica, también es evidente que el paisaje había sido configurado por la sucesión de varias generaciones. La periodificación establecida para Cuicuilco debe considerarse tentativa. De acuerdo con ésta, la ocupación más antigua se remonta hasta el 1200 a.C., en la cuenca hubo una serie de aldeas de agricultores cuya configuración y distribución en el espacio es similar. Hacia 1000-800 a.C. aparecen plataformas de tierra cónico-truncadas con planta ovalada. Los especialistas llaman a estos sitios cabeceras regionales; es decir, eran de mayor jerarquía y funcionaban como centros de integración, lo que resulta en la formación de cabeceras regionales mayores. Si la enorme pirámide de Cuicuilco es expresión de este incremento, entonces ello significa que este nivel de desarrollo se alcanzó entre 800-600 a.C., ya que es la fecha en que se construyó. En caso de ser cierto, el carácter protourbano, característico de este nivel, podría haberse extendido, también, por el Preclásico Tardío hasta el debilitamiento de Cuicuilco entre 100 a.C. y 1 d.C. En este momento comenzó el desarrollo de Teotihuacan, que en el Clásico fue un centro urbano muy importante. (http://www.cnca.gob.mx/cnca/inah/zonarq/cuicuilco.html recuperado el 20/06/05)

Catedral de México. Construida bajo un solar de una primitiva iglesia edificada por Henrán Cortés (y esta a su vez sobre un templo Azteca) fue proyectada por el arquitecto español Claudio de Arciniega en 1573, maestro mayor de la obra, y levantada por Juan Miguel de Agüero --que había sido el arquitecto que construyó la catedral de Mérida-- es sin duda una de las catedrales mas complejas estilísticamente del continente americano. El diseño de la misma esta inspirado en las catedrales españolas de Valladolid, Málaga y Jaén. La planimetría esta concebida como un inmenso rectángulo en el cual la nave del crucero es de idénticas proporciones a la central, mas las naves de capillas laterales, y la altura de las tres naves son dispares. El edificio que no es de gran altura da un aspecto muy masivo al edificio, a pesar de sus dos torres frontales. Pero ese aspecto masivo del que hablamos es típico en muchas de las construcciones latinoamericanas, pues al estar en zona de gran amenaza sísmica no permitía las construcción de edificios muy elevados como las catedrales europeas, siendo el uso de fuertes contrafuertes habitual para una mejor "sujetación" del edificio.

Uno de los elementos mas característicos y destacados de la catedral de México se encuentran en la fachada del sagrario, obra del granadino Lorenzo Rodríguez, que concibe la fachada como un retablo en piedra, trasladando a Mexico la riqueza exuberante del barroco granadino. Ricamente ornamentada, la disposición estilística esta basada en la pilastra, dispuestas en cuerpos y calles como 
si de un retablo se tratara, que se combina con la rica policromia de los materiales autóctonos, como el tezontle y la piedra blanca de Chiluca, aumentando el pictoriscismo de esta fachada.

Santiago Tlatelolco. Tlatelolco -del náhuatl tlatelli, “terraza”, o xaltiloll, "lugar del montón de arena”- fue fundado por los mexicas en 1337 d.C. En 1521 cayó en manos de los españoles y en 1527 se fundó ahí la iglesia del Señor Santiago. A partir de los años sesenta del siglo XX el sitio es conocido como Plaza de las Tres Culturas, ya que reúne valores históricos de tres grandes épocas de la historia nacional: el México prehispánico, el colonial y el moderno.Iglesia de Santiago Tlatelolco. Conserva elementos característicos de la época colonial. En su fachada norte se expresa el sincretismo novohispano: un águila sostiene en sus garras un escudo con los estigmas de San Francisco flanqueados por flechas y macanas prehispánicas; bajo el frontis se ve una cenefa, símbolo mexica de Tlatelolco, sobre la imagen del santo. (Luis Alberto López Wario Arqueología de la Ciudad de México, vol. XI, número 60, pp. 68-76). Tlaltelolco fue uno de los principales y más grandes centros comerciales del México prehispánico. Además del enorme tianguis que abarcaba varios kilómetros a la redonda, fue un importante centro ceremonial. Estaba situado en uno de los principales barrios del imperio al que se conocía como Tlatilulco y muy cerca se encontraba el "tecpan" o cabildo de indios. Consumada la conquista, en 1535, los misioneros franciscanos fundaron ahí el convento de Santiago Apóstol (Patrón de España) junto con el Colegio Imperial de Santa Cruz donde se impartían clases especialmente a los hijos de la nobleza indígena. El colegio, construido durante el periodo del virrey don Antonio de Mendoza con apoyo del arzopispo fray Juan de Zumárraga, contó con grandes maestros como fray Arnoldo Bassacio, fray Bernardino de Saghún, fray Andrés de Olmos y fray Juan de Gaona. Sin embargo, debido a una varios fenómenos tales como inundaciones, epidemias y sobre por la carencia de recursos, la institución fue clausurada a fines del siglo XVIII. A estas doctrinas impartidas por los franciscanos, asistió Juan Diego con gran devoción, motivo que ha contribuido a que se le considere como el centro de la evangelización en nuestro país. Hoy en día, en el ex convento se encuentra la biblioteca de la Secretaría de Relaciones Exteriores. Por lo que respecta al templo, en 1609 fue dedicado a Santiago Apóstol Tlatelolco. El proyecto quedó a cargo de fray Juan Bautista y fue fray Juan de Torquemada quien dirigió la obra. Se dice que había gran parecido entre el rostro del santo que quedó plasmado en dicha iglesia y el de Hernán Cortés. En los años posteriores a la Reforma la iglesia se convirtió en bodega de la Aduana, mientras que el convento y el espacio dedicado al colegio se destinaron como cuartel y prisión militar. Fue hasta 1945 cuando se devolvió la iglesia a los franciscanos. El atrio de esta iglesia 
colonial es una magnífica explanada en donde gracias a algunas excavaciones es posible ver los restos de pirámides que ahí se encontraban. Al fondo se aprecia la moderna torre de la Cancillería. Debido a la presencia de las manifestaciones de estos tres momentos de nuestra historia: la prehispánica, la colonial y la del México moderno, a este espacio se le da el nombre de la Plaza de las Tres Culturas. La construcción de la iglesia es de cal y canto con fachada barroca del siglo XVII. La portada es de cantera y hacia los lados se aprecian dos torres de planta cuadrangular. En la fachada lateral izquierda están dos esculturas de madera, la del Cristo flagelado y la de san Francisco de Asís y Santiago. Por lo que toca al interior del inmueble, la nave es de planta de cruz y en los altos muros hay una serie simétrica de ventanas cerradas adornadas con vitrales abstractos. El presbiterio es de mármol, presidido por un tríptico dorado que ostenta un relieve de madera con la imagen del santo titular. Esto es lo único que quedó del antiguo y majestuoso retablo plateresco realizado por un grupo de escultores indígenas y en donde se encontraban pinturas de Echave Orio. En las pechinas de la bóveda se ven los evangelistas y en la entrada la pila bautismal que es una hermosa concha de piedra labrada. Vale mencionar que en 1965 los arquitectos Mario Pani y Ricardo de Robina llevaron a cabo una restauración. (fuente: http://www.cabin.gob.mx/dgpif/hitoricos/santiago.htm . (c) Derechos Reservados conforme a la Ley, DGPIF, diciembre del 2002).

Bellas Artes. Durante el porfiriato en México surgió entre la alta sociedad una tendencia por imitar los estilos europeos, tanto en costumbres de la vida cotidiana como en modelos arquitectónicos. Esto dio como resultado que, a principios de este siglo, se ideara el proyecto para la construcción del nuevo Teatro Nacional. Así, se demolió el que ya existía y el 1 de octubre de 1904, frente a la Alameda Central, se comenzó la construcción de los cimientos del que se convertiría en el Palacio de Bellas Artes. El proyecto fue realizado por el arquitecto italiano Adamo Boari, quien diseñó un edificio que incorporaba los avances tecnológicos de los mejores teatros de la época. El edificio se caracterizaba por organizar las salas en torno a un gran hall, rematado por una triple cúpula situada entre el vestíbulo y la sala de espectáculos. Esta sala tendría forma de embudo, para lograr así los mejores efectos acústicos y visuales. Su cupo sería de 1791 personas distribuidas entre palcos aislados, generales, lunetas y galerías. También contaría con un palco presidencial, situado exactamente a media sala, con dos elevadores privados y un gabinete de aseo. La orquesta se ubicaría a nivel inferior de la luneta. Se proyectó un escenario de 24 metros de longitud, con instalaciones mecánicas completas. Habría también una gran sala de fiestas, comunicada con siete loggias y terrazas, un restaurante y un acceso cubierto para descender de los carruajes. 
Originalmente la construcción del edificio duraría cuatro años, pero se fue alargando a causa de los hundimientos del terreno y del movimiento armado de 1910. Hacia 1915 era poco lo que se hacía; Boari deja el país en 1916 y a lo largo de los siguientes tres lustros se hicieron algunos trabajos de poca envergadura, hasta que se reinician las obras en 1932, bajo la dirección del arquitecto mexicano Federico Mariscal, quien las concluyó totalmente en marzo de 1934. (fuente: Museo del Palacio de Bellas Artes, Museo Nacional de Arquitectura).

Conjunto Habitacional Nonoalco-Tlatelolco. En la búsqueda de una solución a la demanda de vivienda, urbanistas y arquitectos mexicanos optaron por aplicar los modelos multifamiliares que representaban la mejor alternativa para proporcionar techo a cientos de familias en un espacio relativamente pequeño y con opciones de crédito para su rápida adquisición. De esta forma surgieron los conjuntos y unidades habitacionales, los cuales inaugurarían significativamente desde entonces un nuevo patrón habitacional en la Ciudad de México. Entre 1962 y 1964 se construyó el Conjunto Habitacional Adolfo López Mateos Nonoalco Tlatelolco, a cargo del arquitecto Mario Pani. Dicho conjunto se constituyó como el gran proyecto revolucionario de vivienda en cuanto al diseño y funcionalidad en la capital de la República. Fue en el sexenio del presidente Adolfo López Mateos cuando se consolidó esta megaobra, la cual estaba destinada principalmente a miembros de la entonces pudiente clase media. La unidad se edificó en el norte de la Ciudad de México rodeada de excelentes vías de comunicación, pues estaba flanqueada al poniente y al oriente por las importantes avenidas Insurgentes y Paseo de la Reforma, respectivamente y, en el extremo norte llegaba a la calle de Manuel González y desde el sur comenzaba en Ricardo Flores Magón. Además, por ella cruzaban el actual eje de Guerrero y San Juan de Letrán, mejor conocido como el Eje Central Lázaro Cárdenas. Por sus alternativas para desplazarse y por la cercanía al corazón de la ciudad, así como por la gran calidad de los servicios que ofrecía desde sus inicios, Tlatelolco se constituyó como la mejor opción de compra en la categoría multifamiliar. Bastaba dar un cuatro por ciento de enganche del monto total para hacerse acreedor de uno de los diversos tipos de departamentos, los cuales oscilaban entre los 100 y los 175 mil pesos de los años 60. Las mensualidades comprendían un costo de únicamente 20 por ciento del enganche otorgado y en ellas se incluían implícitamente los gastos de amortización de saldo y los intereses; servicios de administración y mantenimiento, tales como la limpieza y la recolección de basura; cuidado y conservación de jardines, elevadores, alumbrado de calles, pasillos y cubos de los edificios. Además de la vigilancia total del conjunto, seguro de daños, el pago del impuesto predial y el nada despreciable derecho por consumo ilimitado de agua. 
Distribuidor Vial San Antonio (2002). (De 3.5 kilómetros de longitud que costará 700 millones de pesos, dinero que se tomará de los mil 500 millones que se pensaba destinar a la primera etapa de la megaobra). Circulan más de 3 millones de vehículos cada día. Se estima que en las horas de más denso tráfico los vehículos avanzan por las principales arterias de la ciudad de México a una velocidad de 13 y 20 kilómetros por hora.

Teodoro González de León. Nació en la Cd. de México el 28 de mayo de 1926. Realizó sus estudios en la Antigua Academia de San Carlos (UNAM) de 1942-1947, Paralelamente a sus estudios se inició en la vida profesional. Primero como dibujante en los talleres de Carlos Obregón Santacilla y Carlos Lazo y más adelante con Mario Pani (1945-47). Fue becario del gobierno francés y trabajó durante 18 meses en el taller de Le Corbusier (1947-48). Allí participó en la elaboración de los planos de varios trabajos y como supervisor de dos grandes obras: la Unidad de Habitación de Marsella y la Planta de Manufactura de St. Dié, Francia (1948-49). Desde su regreso a México, a principios de los cincuentas, ha desarrollado una actividad profesional ininterrumpida, primero en el campo del urbanismo y de la vivienda popular, y posteriormente en el de los grandes edificios públicos y privados. Inicia un periodo de asociaciones con Abraham Zabludovsky, siendo el Conjunto Habitacional "Mixcoac-Lomas de Plateros", 1969-1971, el primero de una serie de unidades de vivienda. Entre 1974 y 1982 proyecta con Zabludovsky importantes edificios públicos, como la Delegación Cuauhtémoc, El Colegio de México, la sede del INFONAVIT, la Universidad Pedagógica y el Museo Rufino Tamayo. En Villahermosa realiza destacadas obras como el Parque Tomás Garrido Canabal, la Biblioteca Pino Suárez y el Centro Administrativo, en colaboración con J. Francisco Serrano, 1984-1987. Premio Nacional de Artes, 1982. Miembro de Número de la Academia de Artes, 1984, y Miembro del Colegio Nacional, 1988. En la década de los noventa propuso interesantes edificaciones como el Edificio del Fondo de Cultura Económica, la Unidad de Servicios Turísticos de El Tajín y el Conservatorio Nacional de Música. Ganó en compañía de J. Francisco Serrano el concurso para la nueva embajada de México en Berlín. Realiza el Corporativo Arcos Bosques en 1990-1996, junto con Francisco Serrano.

Francisco Serrano. Nació en la Ciudad de México el 30 de octubre de 1937. Egresó de la Universidad Iberoamericana en 1960 y fue integrante de la Academia Nacional de Arquitectura y de la Sociedad de Arquitectos Mexicanos.

Empezó a trabajar muy joven. Fue alumno de Augusto H. Álvarez y, después, de JuanSordo Madaleno. La práctica profesional la inició solo, y con su padre, en 1959. Dentro de sus obras más representativas se encuentra la Universidad Iberoamericana, realizada entre 1983 y 1988; el Centro 
Corporativo Bosques, proyectado junto con los arquitectos Teodoro González de León y Carlos Tejeda, entre 1991 y el 2000; y la Embajada de México en Alemania, hecha entre 1997 y el 2000. Su más reciente obra es el nuevo edificio académico de la Universidad Iberoamericana. Premios internacionales que ha recibido el proyecto arquitectónico de la UIA Ciudad de México, antes del nuevo edificio académico:

- UIA Ciudad de México: Premio Especial del Consejo Regional de Plovdiv y Medalla de Plata, en la Quinta Bienal Mundial de Arquitectura, en Sofía, Bulgaria (1989).

- División de Ingeniería y Extensión Universitaria de la UIA (edificios F-G): Premio Especial del Alcalde de Viena, Austria, Medalla y Diploma, en la Séptima Trienal Mundial de Arquitectura INTERARCH’94, en Sofía, Bulgaria (1994).

- División de Ingeniería y Extensión Universitaria de la UIA Ciudad de México (edificios F-G): Primer Lugar Categoría Diseño Arquitectónico, en la Segunda Bienal de Arquitectura y urbanismo de Costa Rica, en San José, Costa Rica (1994).

- División de Ingeniería y Extensión Universitaria de la UIA Ciudad de México (edificios F-G): Mención en la Tercera Bienal de Arquitectura Mexicana, en la Ciudad de México (1994).

- Reconocimientos Establecimiento Amigo 2000 y 2001.

Agustín Hernández. Nace en la Ciudad de México en 1924. Realiza sus estudios en la Escuela Nacional de Arquitectura, UNAM, obteniendo su título en 1954. Inicia su quehacer profesional proyectando buen número de casas habitación y edificios de oficinas. Entre 1954 y 1968 desarrolla una labor docente en la Escuela Nacional de Arquitectura, UNAM, al frente del Taller $\mathrm{N}^{\circ} 8$. Construye la Escuela de Ballet Folklórico en 1968, que se significa por ser su primer edificio dentro de la arquitectura escultórica. Una serie de casas habitación muestran su creatividad, al utilizar diversos módulos, formas y volúmenes. La Casa en el Aire, 1995, puede señalarse como el compendio de estas propuestas. Gana buen número de concursos, donde destaca el Heroico Colegio Militar en colaboración con Manuel González Rul, 1975. La audacia estructural de su Taller de Arquitectura, 1972-1975, le otorga un amplio reconocimiento. Académico de Número de la Academia de Artes, 1991. En fechas recientes inicia el diseño y realización de mobiliario y escultura. Corporativo Calakmul, Santa Fe, Ciudad de México. Agustín Hernández, 1994-1997. 